\title{
Review of approaches for the estimation of sensible heat flux in remote sensing-based evapotranspiration models
}

\author{
M. M. Prakash Mohan $\odot$, Rajitha Kanchirapuzha $\odot$,* \\ and Murari R. R. Varma $\odot$
}

BITS Pilani Hyderabad Campus, Department of Civil Engineering, Hyderabad, India

\begin{abstract}
We recapitulate the approaches of sensible heat flux $(H)$ estimation, which is a critical parameter in the remote sensing (RS)-based evapotranspiration (ET) models. We propose a classification scheme for the ET models considering their distinctions in approaches for the estimation of $H$. Adhering to the proposed classification scheme, the theoretical backgrounds of $H$ estimation in the single-source and two-source RS-based ET models are discussed in brief, along with their unique characteristics. We addressed the role of critical parameters that influenced the $H$ computation under each model and presented the related progress in the research. The importance of data assimilation techniques, as well as the application of unmanned aerial vehicles for the uninterrupted estimation of turbulent heat flux, are discussed in the context of single-source and two-source models. The influence of scale on the validation of the models and the impact of the aggregation methods are discussed. We compared the performance of the popular ET models for the estimation of $H$, utilizing the information obtained from peer-reviewed articles. The limitations related to the RS datasets in terms of spatial and temporal resolution and the scope of alleviating the shortcomings using the future satellite missions are discussed. We conclude by pointing toward the current challenges and the prospective domain of research, which needs to be addressed critically in the future. () 2020 Society of PhotoOptical Instrumentation Engineers (SPIE) [DOI: 10.1117/1.JRS.14.041501]
\end{abstract}

Keywords: sensible heat flux; surface energy balance models; evapotranspiration; remote sensing; single-source models; two-source models.

Paper 200065V received Jan. 23, 2020; accepted for publication Oct. 5, 2020; published online Oct. 15, 2020.

\section{Introduction}

The sensible heat flux $(H)$ and latent heat flux $(\lambda E T)$ of the energy balance equation, have a notable role in various domains of applications spanning from climate change to water resource management. In the remote sensing (RS) perspective, sensible heat flux computation gained more attention because of its sensitivity and computationally complex nature among all other components in the surface energy balance equation. ${ }^{1,2}$ The sensible heat flux parameter has a significant impact on the $\lambda E T$ values as most of the RS-based models calculate $\lambda E T$ as a residual of the surface energy balance equation as follows: ${ }^{3}$

$$
\lambda E T=R_{n}-G-H
$$

where $R_{n}$ is the net radiation $\left(\mathrm{Wm}^{-2}\right), G$ is the soil heat flux $\left(\mathrm{Wm}^{-2}\right), H$ is the sensible heat flux $\left(\mathrm{Wm}^{-2}\right)$, and $\lambda E T$ represents the latent heat flux $\left(\mathrm{Wm}^{-2}\right)$.

The RS-based evapotranspiration (ET) models attained much importance in the last four decades due to the accelerated advancements in the satellite RS technology. Though the RSbased models are preferred to other approaches due to their better estimation of $H$ capability under water-stressed conditions, there exist many challenges, such as lack of techniques for

*Address all correspondence to Rajitha Kanchirapuzha, rajitha@hyderabad.bits-pilani.ac.in 
aerodynamic temperature measurements, use of radiometric temperature as a surrogate to aerodynamic temperature, and existence of heterogeneous partial canopy cover conditions. ${ }^{4}$

This review is an attempt to organize the outcomes obtained from the research carried out in the realm of sensible heat flux computation focusing on RS-based ET models. This review targets to create a comprehensive link between the approaches through a new classification scheme based on their mode of operation for the estimation of sensible heat flux.

\subsection{Hybrid Nature of Sensible Heat Flux Estimation Approach}

The sensible heat flux estimation could not be considered as a sole RS approach as many of the models utilize the combination of micrometeorological and RS concepts. Though the RS models consider land surface temperature (often referred as LST or $T_{s}$ or $T_{\text {rad }}$ ) as the primary boundary condition, they could not account for the uncertainty due to canopy cover and turbulence in the atmosphere. The parameters such as aerodynamic roughness of the surface and the wind velocity are also crucial under the non-neutral conditions of the atmosphere. Therefore, the estimation of $H$ needs a hybrid approach by incorporating RS and micrometeorological concepts. This review mainly focuses on the RS aspects of the hybrid approach.

\subsection{Organization of the Paper}

This review starts with the concepts of resistance-based models with historical developments that guided the evolution of RS-based models. The RS-based ET models grouped under the proposed classification scheme are linked to form a comprehensive account of the progress in the sensible heat flux research in the succeeding sections. This review further discusses the importance of data assimilation techniques, the influence of scale changes on field validation of the models, and the recent developments in the use of unmanned aerial vehicles (UAVs) for the estimation of turbulent heat flux. This review concludes with a record of historical milestones along with the current developments in sensible heat flux related research.

\section{Concepts of Resistance-Based Models for the Estimation of Sensible Heat Flux}

The concept of resistance in plant physiology dates back to 1900, and later Monteith proved that the Ohm's law-based resistance approach could simplify the estimation of $H$ from natural surfaces. ${ }^{5}$ The "Penman-Monteith" (PM) equation ("big-leaf" approach), which follows the resistance-based concept, was the simple model used in the one-dimensional single-source descriptions of ET process, which is expressed as ${ }^{6}$

$$
H=\frac{\rho C_{p}\left(T_{0}-T_{a}\right)}{r_{a}^{a}},
$$

where $r_{a}^{a}$ is the aerodynamic resistance between the source (canopy) and the reference height, $T_{0}$ is the aerodynamic temperature $(\mathrm{K}), T_{a}$ is the air temperature $(\mathrm{K}), C_{p}$ is the specific heat of air at constant pressure $\left(\mathrm{J} \mathrm{kg}^{-1} \mathrm{~K}^{-1}\right)$, and $\rho$ is the mean air density $\left(\mathrm{kg} \mathrm{m}^{-3}\right)$. One of the well-known practical application of the big-leaf approach is the FAO-56 (Irrigation and Drainage Paper No. 56) of Food and Agricultural Organisation. ${ }^{7}$ The performance of big-leaf based models mainly constrained to the rational calculation of an "excess resistance" term quantified by $k B^{-1}$. The term $k B^{-1}$ [which is equal to $\ln \left(z_{0 m} / z_{0 h}\right)$ ] explains the difference between the height of the equivalent surfaces for momentum absorption $\left(z_{0 m}\right)$ and heat transfer $\left(z_{0 h}\right){ }^{8}$

The inability of the big-leaf concept to represent the canopy resistance for sparse vegetative conditions led to the development of two-source models where the estimation of component fluxes of soil and vegetation is essential. ${ }^{9}$ The two-source conceptual framework incorporated the influence of soil and vegetation components separately and categorized as series and parallel ET models. ${ }^{10}$ The presence of canopy structure with stacked multiple layers became the impetus for the development of multi-source models. The turbulence within the canopy and 
the counter-gradient fluxes, which are prominent in multi-layered canopies, make the multilayered models complicated and limited. ${ }^{11}$

\section{Importance of Radiometric Temperature and Aerodynamic Temperature in ET Models}

The radiometric surface temperature $\left(T_{s}\right)$ derived from RS platforms is used as a proxy for aerodynamic temperature $\left(T_{0}\right)$ in RS-based models. ${ }^{3}$ The single-source models primarily rely upon the relationship, which accounts for the difference between $T_{0}$ and $T_{s}$. In the partially vegetated areas, the difference between $T_{s}$ and $T_{0}$ can even reach up to $10^{\circ} \mathrm{C}$ resulting in the overestimation of $H \cdot{ }^{12-16}$ To overcome this difference, an extra resistance term $r_{\mathrm{ex}}$, derived from $k B^{-1}$ was incorporated in the bulk transfer equation. ${ }^{17}$ Due to the uncertainty regarding the dependency of $k B^{-1}$ on surface temperature, wind speed, and ground cover conditions, many methods were proposed without incorporating $k B^{-1}$ parameter. ${ }^{14,18-20}$ Among them, the temperature gradientbased approaches reduced the errors contributed by the air temperature and successfully adopted in many of the current popular RS-based models. ${ }^{19,21}$

\section{Atmospheric Stability Corrections and Aerodynamic Resistance}

The earlier ET models assumed the existence of neutral atmospheric stability with homogeneous land surface temperature and stable wind velocity profile at the near-surface layers. The occurrence of such neutral stability condition is rare in heterogeneous canopy cover with varying soil moisture conditions. ${ }^{22}$ As the soil moisture depletes, the canopy temperature would rise, and the air density above the canopy would reduce, and it creates unstable conditions with increased heat transport. Similarly, at unstable conditions, the rate of decrease of air temperature with an increase in elevation is higher than the adiabatic lapse rate, which promotes the increased exchange of sensible heat flux. Contrary to this, at stable conditions, the rate of heat transfer decreases. The incorporation of atmospheric stability correction procedures in the estimation of aerodynamic resistance $\left(r_{\mathrm{ah}}\right)$ accounted for the aforementioned micrometeorological changes that influenced the sensible heat flux computations. ${ }^{23,24}$ Numerous studies proposed MoninObukhov (MO) stability parameter $(\zeta)$ or Richardson's number $(R i)$ as the indicator of the atmospheric stability conditions. ${ }^{16,17,19,25,26}$ Generally, an iterative procedure is adopted while using $\zeta$ as a quantifier for atmospheric stability changes. Instead of $\zeta$, many researchers had used $R i$ to avoid the iterative procedures in various surface energy balance models., ${ }^{3,27,28}$ Though the Richardson's number found its place in various studies, it was not usually preferred over $\zeta$ since it is an unknown function of height and often approaches a constant value for near-surface layer applications. ${ }^{25}$

\section{Classification of ET Models Based on Sensible Heat Flux Estimation Approach}

The classification scheme unlocks opportunities to understand the characteristics of models systematically. One of the well-known classification methods developed by Courault et al. categorized the ET models into four different classes based on the complexity, considering the balance between the empirical and physical approaches applied in the models. ${ }^{29}$ The four categories are direct empirical methods, the residual methods of the energy budget, the deterministic methods, and the vegetation index-based methods. The direct empirical category includes RS-based semiempirical ET models, and the residual models use empirical and physical modules that are operational. The deterministic models are more complex models where the RS data are assimilated at different modeling levels. The vegetation index-based category of models uses RS data to compute reduction factors (e.g., crop coefficient and Priestley-Taylor coefficient) to estimate ET. Later, a new classification scheme by Bhattarai et al. grouped single-source energy balance models into three categories based on the methodology adopted for the estimation of $H$. 


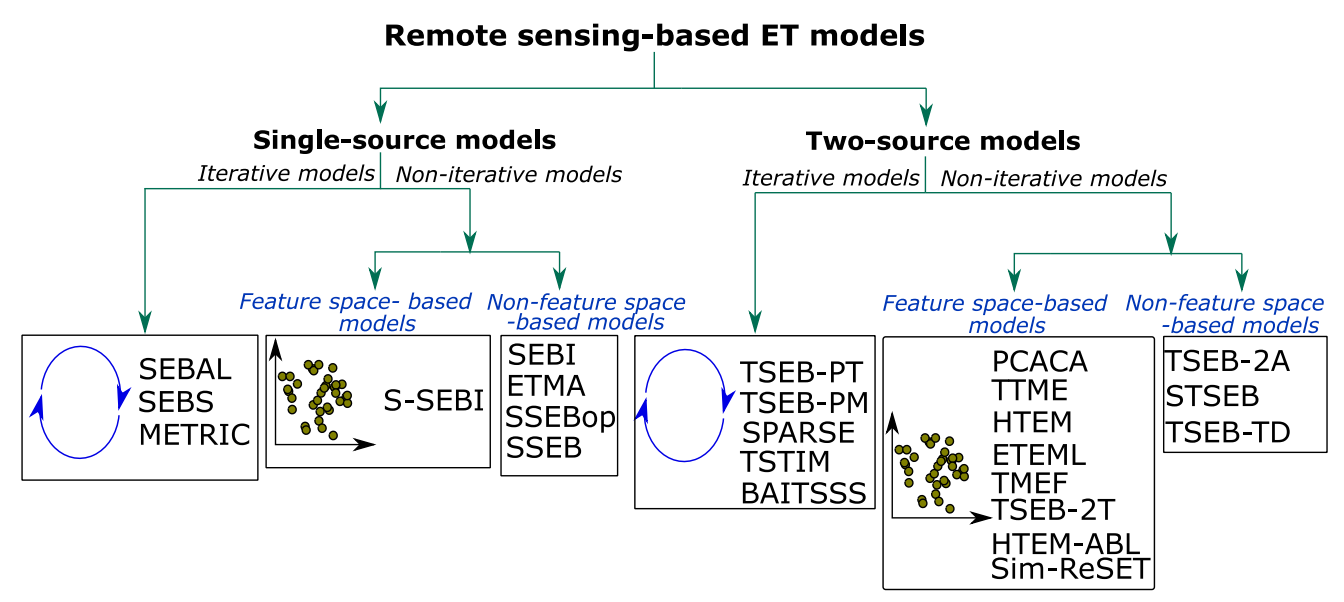

Fig. 1 Classification of RS-based ET models based on sensible heat flux estimation approaches.

The categories are hot and cold pixel-based full energy balance models, excess resistance-based full energy balance models, and partial energy balance models. ${ }^{30}$

The current population of RS-based ET models that include single- and multi-source models demands a generic theme of classification that facilitates a comprehensive approach with a better distinction between the classes. The approach should also improve the flexibility to update future developments. In view of these requirements, this review proposes a classification scheme for RS-based ET models as an extension of the classification scheme by Bhattarai et al. The current classification scheme considers the sensible heat flux estimation approach as the criterion for categorizing the models.

The classification scheme (Fig. 1) broadly divides the models into iterative and non-iterative models. The iterative models estimate $H$ using an iterative procedure based on an initialization and termination condition. The non-iterative models are further classified into feature spacebased and non-feature space-based models. The feature space-based models among non-iterative category utilize two-dimensional feature space [e.g., vegetation fraction cover-land surface temperature (VFC-LST) space] to estimate the parameters essential for the models. The noniterative, non-feature space-based models are simple and straightforward that retrieve the model parameters without the aid of feature space or iterative procedure.

\section{Sensible Heat Flux Estimation Approaches in Single-Source ET Models}

Statistics of the peer-reviewed articles published during the last 10 years (source: Ref. 31) revealed that the surface energy balance algorithm for land (SEBAL), mapping evapotranspiration at high resolution with internalized calibration (METRIC), and surface energy balance system (SEBS) are the popular models of the single-source category [Fig. 2(b)]. Though these models are more suitable for semiarid regions, the spatial distribution of the sites chosen for executing these models are spread across all the climatic regions except polar group (as per Köppen-Geiger climate classification ${ }^{32}$ ). Refer to Fig. 2(a) for the spatial distribution of sites across the globe where popular models were tested.

\subsection{Sensible Heat Flux Estimation Approaches in Iterative Single-Source ET Models}

The SEBAL ${ }^{19}$ METRIC,${ }^{21}$ and SEBS ${ }^{33}$ are the iterative models that follow the $H$ estimation procedure as a hybrid approach using micrometeorological and RS concepts. METRIC is an improved version of SEBAL that provides relatively more accurate estimates of ET at a higher spatial resolution and more suitable for advective conditions. The similarity of SEBAL and METRIC in their theoretical framework, underlying assumptions, and data requirements for 


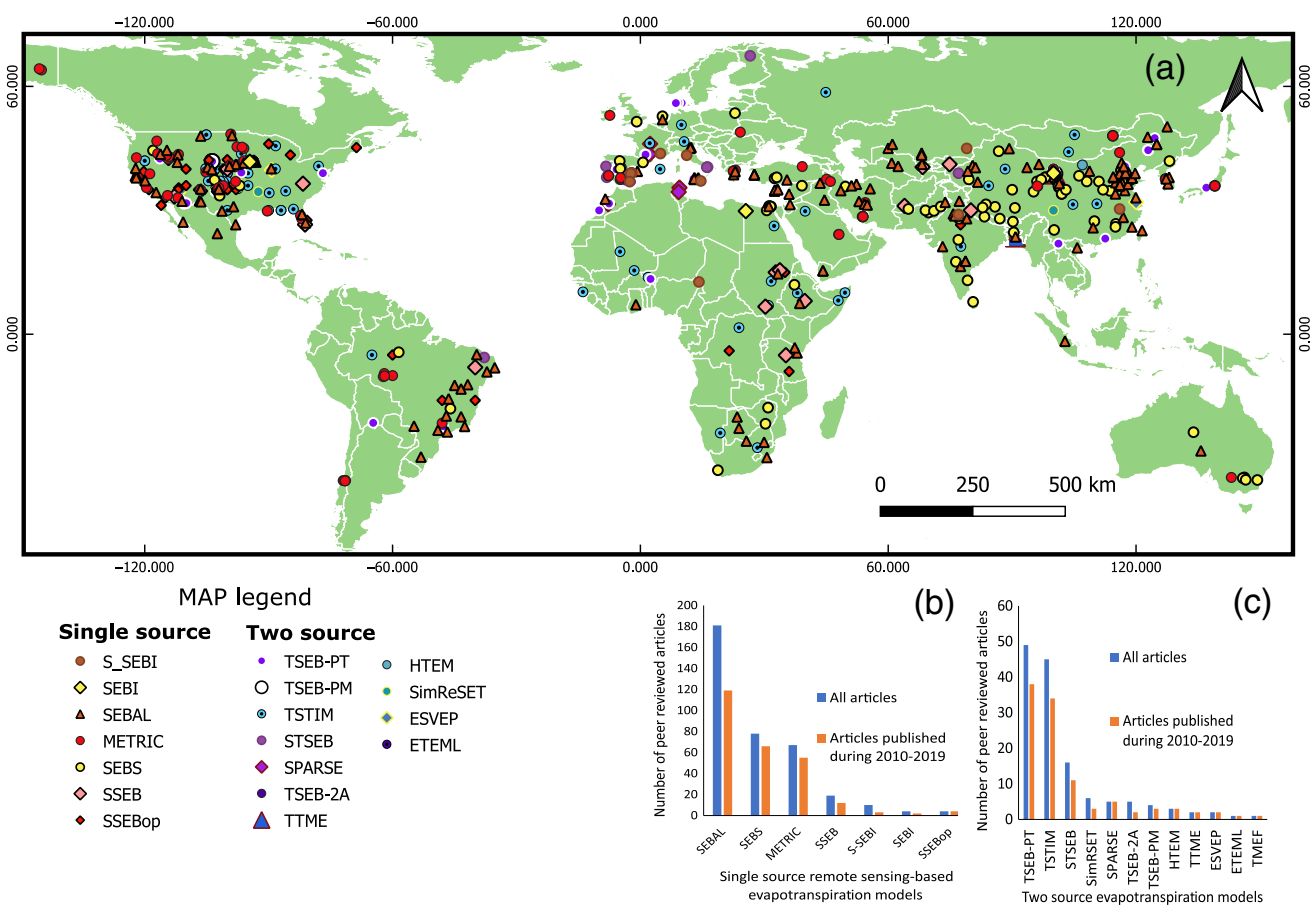

Fig. 2 (a) Study sites across various continents for single-source and two-source models; (b) statistics of articles published in peer-reviewed journals focusing RS-based single-source ET models; and (c) statistics of articles published in peer-reviewed journals focusing RS-based two-source ET models. Prepared using the data collected from Ref. 31.

$H$ estimation makes both the models compatible with any common modifications. ${ }^{19,34}$ The limitations of SEBAL to operate at different atmospheric stability regimes and its semiempirical nature resulted in the development of a physically based model, SEBS. ${ }^{16}$ The SEBS uses relative evaporation fraction for computing the surface energy balance components using calibration limits called "wet" and "dry" limits using non-subjective procedure (use of equations). In contrast, METRIC and SEBAL use reference ET fraction, which is calibrated using hot and cold pixels (anchor pixels) selected by the subjective judgment of the user.

In SEBAL and METRIC, the two anchor pixels from the scene with extreme climatic and hydrological conditions (well-irrigated vegetation and dry open land) employed to calculate near-surface temperature gradient $(d T)$ for the estimation of $H$. Stability corrected $r_{\text {ah }}$ and stabilized $d T$ values were obtained at the calibration pixels during the iterative stability correction procedure using MO theory. These calibration pixels establish an empirical linear relationship between $d T$ and $T_{s}$ that further calculates $H$ for every $T_{s}$ values. The iterative autocalibration procedure called calibration using inverse modeling of extreme conditions (CIMEC) mitigate the effect of error that occurred in $T_{s}$ measurements METRIC and SEBAL. ${ }^{35}$ Due to the lack of arid open land with very high radiometric heating in agricultural areas, the assumption of zero latent heat flux $\left(\lambda E T_{\text {hot }}\right)$ in SEBAL was modified as non-zero latent heat flux in METRIC. This modified assumption also accommodates the presence of residual moisture content at hot pixels and avoid the underestimation of $H \cdot{ }^{36}$ Similarly, the assumption that equated the ET at the cold pixel to 1.05 times the reference ET was not considered in METRIC due to its non-applicability during early growing seasons as well as non-growing seasons. ${ }^{34}$ The subjective nature of the anchor pixel selection process and the higher variability in the surface conditions for higher $T_{s}$ values make the selection of hot pixels difficult. ${ }^{37}$ The utilization of available energy $\left(R_{n}-G\right)$ as an additional input along with NDVI and $T_{s}$ were useful in retrieving the candidate pixels with distinct variation. ${ }^{38}$ By considering the soil moisture and available energy as influencing auxiliary parameters for the endmember selection process, Mohan et al. ${ }^{39}$ proposed the integration of synthetic aperture radar (SAR) derived soil moisture into SEBAL for anchor pixel selection process. The semiautomatic statistical approach by Allen et al., a fully automatic procedure 
based on exhaustive search algorithm by Bhattarai et al. and the modified version ASEBAL with an automated endmember selection process are the recent related developments in the domain of anchor pixel selection process. ${ }^{40-42}$

Single-source models use aerodynamic resistance as an essential parameter that captures the spatial variability of $H$. The aerodynamic resistance and its component parameters (surface roughness lengths) are characterized by spatially varying canopy architecture. ${ }^{43}$ The roughness length calculation is sensitive to the changes in wind speed, soil, and canopy temperature and may result in significant temporal variability. To account for these, a physically based model was developed by Su et al. ${ }^{16}$ to incorporate the surface condition and the aerodynamic variables from the ground. Such physical models require detailed information at the ground level at all scales of applications, and the scaling of the models from local to regional scales demanded a considerable amount of ground sampling.

RS-based ET models explicitly do not consider soil moisture variations for the estimation of $H$, relying upon the assumptions that the $T_{s}$ and NDVI indirectly consider and incorporate the influence of soil moisture. ${ }^{44}$ However, at water-stressed conditions, the radiometric temperature is inadequate to represent the effect of soil moisture and biophysical parameters. At limiting conditions of soil moisture, $z_{0 h}$ increases whereas $z_{0 m}$ decreases, which leads to the changes in $k B^{-1}$ values. The influence of $k B^{-1}$ on varying soil moisture conditions contributed to the development of various empirical approaches, which included the soil moisture information into the bulk transfer equation in SEBS. ${ }^{44-46}$ In METRIC, the incorporation of soil moisture related parameters is done through the Priestley-Taylor parameter $\left(\alpha_{\mathrm{PT}}\right)$ by choosing a value different from the usual value of 1.26 according to the changes in soil moisture content. This modified approach is often referred to as wMETRIC. ${ }^{47}$

In the case of METRIC and SEBAL, the estimate of $R_{n}$ and $H$ had a constant bias across the scene. The radiometric accuracy of the satellite data, the assumptions related to the models, and the uncertainties in the parameters used for the estimation of surface roughness and wind speed were the significant factors that influenced the magnitude of the bias. ${ }^{40}$ The application of METRIC and SEBAL in arid and non-agricultural areas resulted in the overestimation of $H$, inferring that both the models are not suitable for sites with extreme climatic conditions. ${ }^{48,49}$ Unlike SEBAL and METRIC, the application of SEBS in non-agricultural areas becomes versatile due to its non-subjective approach for the selection of the extreme wet and dry limits. Among the single-source models, SEBS is more sensitive to changes in the surface to the air temperature gradient $\left(T_{s}-T_{a}\right)$ for the computation of $H$ compared to the individual effect of $T_{s}$, and it is more sensitive than the surface aerodynamic parameters. ${ }^{50-52}$ The SEBAL and METRIC avoided the direct use of $T_{s}$ by adopting the near-surface temperature gradient $(d T)$ estimated by CIMEC process, which eliminates the systematic bias in the calculated $T_{s}$ values. ${ }^{53}$ When comparing the performance of the single-source iterative models, the major difference was observed in the estimation of $H$. SEBAL consistently underestimated $H$ and showed more than $65 \%$ variation from reference eddy covariance (EC) measurements. ${ }^{54}$ The deviations for METRIC and SEBS were $34 \%$ and $56 \%$, respectively. ${ }^{55,56}$ For $\lambda E T$, all three models exhibited less variations (SEBAL-13.5\%, METRIC-15.1\%, and SEBS-20.6\%) compared to $H$. The higher deviations of $H$ in these models could be explained by their inability to partition the soil and vegetation component fluxes and their extreme sensitivity to the calibration pixels. A modified approach called M-SEBAL was introduced to decrease the bias in $H$ in SEBAL by determining the anchor pixels from VFC-LST space. This approach minimized the deviation of $H$ from $65 \%$ to $24.8 \%{ }^{54}$ The above values are only for reference to show the general trend of each model outputs.

\subsection{Sensible Heat Flux Estimation Approaches in Single-Source Non-Iterative ET Models}

The single-source models of non-iterative category compute $H$ as a residual of other energy balance components, using evaporative fraction (EF). Models such as surface energy balance index (SEBI), simplified surface energy balance index (S-SEBI), simplified surface energy balance (SSEB) model, and operational simplified surface energy balance (SSEBop) model are listed under this category. Among these models, SSEB has tested for all climatic zones except the polar zone, whereas its operational version SSEBop was tested only for tropical and 
dry climatic zones. Minimal studies are available for SEBI and tested for very few locations grouped under continental and dry climatic zones. The S-SEBI, the simplified version of SEBI, has successfully applied at dry, temperate, and continental zones.

\subsubsection{Feature space-based models}

S-SEBI is a simplified operational RS-based model, in which the extreme temperatures at the boundary conditions are extracted from the $T_{s}$-reflectance spectral space. The two assumptions followed in S-SEBI are the existence of constant atmospheric conditions as well as the presence of calibration pixels within the area of application.$^{57} \mathrm{~S}$-SEBI utilizes $T_{s}$-reflectance feature space to determine EF without any ancillary data sets or meteorological data from the field. ${ }^{57,58} \mathrm{~S}$-SEBI model is empirical, which restricts the extensive application of the model to global scales. Hence it is essential to calibrate the model for diverse climatic conditions. For instance, in semiarid areas with vegetation, EF exhibits very low values as a water deficit indicator, and therefore, a non-evaporative fraction-based approach was proposed for estimating sensible heat flux. ${ }^{59}$ Since S-SEBI is a pure image-based model that entirely relies upon the feature space for model parameters, the current focus of the research is to reduce the atmospheric and sensor related errors from the feature space. The use of surface albedo calculated by weighted surface reflectance approach is generally adopted for the feature space creation in S-SEBI. To improve its performance, a proper view zenith angle correction is essential. The surface broadband albedo calculated by the integration of bidirectional reflectance distribution function was found to be effective for the estimation of surface energy balance components in S-SEBI ${ }^{60}$ Regarding the performance of the model compared to other single-source models, S-SEBI showed comparable performance with SEBAL and METRIC at arid conditions and the model was less suitable for wet conditions as it overestimated $H .^{61}$

\subsubsection{Non-feature space-based models}

The SEBI became the precursor of RS-based ET models, which laid the strong theoretical foundations for all the present-day single-source models. It is the modified parametrization of crop water stress index developed by Jackson et al. ${ }^{62}$ and obtained by simultaneously solving the energy balance equation and the profile equations for sensible heat flux and latent heat flux at two extreme conditions of potential ET and zero ET in the study area. SEBI estimates the $H$ based on the difference between the plant surface temperature and air potential temperature at the top of the atmospheric boundary layer. ${ }^{63}$ The model is unique because of its capability to handle situations when sufficient wet and dry pixels are not available in the study area. It uses the temperature difference obtained either from radio soundings or weather prediction models for estimating boundary conditions. The requirement of essential meteorological variables from the upper boundary of planetary boundary layer (PBL) made the model less operational as well as less compatible for RS datasets. ${ }^{64}$

SSEB is a regional scale model that inherits the concept of "near-surface temperature gradient $(d T)$ " from SEBAL and METRIC for the actual ET estimation. The linearity assumption of sensible heat flux in SEBAL ( $H$ is proportional to $d T$ ) is extended for the estimation of latent heat flux in SSEB. The calibration pixels that correspond to zero ET and potential ET are used to establish a linear relationship between the temperature gradient and the actual ET, which further employed to derive the EF for any pixel within the study area. The SSEB model was modified to SSEBop by predefining the hot and cold extremes, which enhanced its potential as a large-scale operational RS model. ${ }^{65}$ The models such as SSEB, SEBAL, and METRIC designate the candidate pixels for a limited period, during which a uniform hydroclimatic condition exists. In actual field conditions, the candidate pixels change their locations within the same study area as per the variations of environmental factors. Contrary to this, the assumption of changing candidate pixels was discarded in SSEBop as it found to be less influential in the context of the accuracy of outputs obtained. Therefore, the candidate pixels were predefined and remained as same for the entire period for which the fluxes are estimated. The underestimation of $H$ at dry open areas is a major limitation of the model. At vegetated areas, SSEB exhibits comparable performance with SEBAL and METRIC. ${ }^{66}$ 


\section{Sensible Heat Flux Estimation Approaches in Two-Source ET Models}

The two-source approach is more robust than the single-source approach due to its ability to partition the canopy and soil flux components. It also handles the influences of atmospheric and the sensor look angle effectively. The two-source models predict more accurate values of $H$ in sparse canopy conditions and provide a reliable physical framework for capturing the variations of the aerodynamic resistance compared to single-source models. ${ }^{67,68}$ The two-source models are differentiated based on the approaches adopted for partitioning the directional radiometric surface temperature into canopy and soil temperatures $\left(T_{C}\right.$ and $\left.T_{S}\right)$. Among iterative models, two-source energy balance-Priestley-Taylor (TSEB-PT) and two-source time integrated model (TSTIM) and its operational versions such as atmosphere-land exchange inverse (ALEXI) model were tested for all climatic zones except polar. Only limited studies are available for two-source energy balance-Penman-Monteith (TSEB-PM), and it was tested only for dry climatic conditions. Among non-iterative models, the best performing model hybrid dual-source scheme and trapezoid framework-based evapotranspiration model (HTEM) was tested for dry and continental climates only. The two-source energy balance model-two angle (TSEB-2A) that utilizes two-directional surface temperature has few studies available and was tested for dry, tropical, and continental climates [refer Fig. 2(a)]. The statistics of the peer-reviewed articles published during the last 10 years showed that the TSEB-PT model gained more attention compared to other RS-based TSEB models [Fig. 2(c)].

\subsection{Sensible Heat Flux Estimation Approaches in Iterative Two-Source ET Models}

The TSEB-PM ${ }^{69}$ and TSEB-PT ${ }^{70}$ are the two different approaches, under the iterative category of two-source models, which differ mainly based on the fundamental equation used to estimate the initialization parameter $\left(\lambda E_{C}\right)$ for iteration. The TSEB-PT model calculates $\lambda E_{C}$ by the PT equation, assuming potential transpiration whereas, in TSEB-PM the calculation follows PM equation. In TSEB-PT, the iteration begins by assigning the value of PT coefficient $\left(\alpha_{\mathrm{PT}}\right)$ as 1.26, which progressively assumes smaller values in the subsequent iterations. The iteration procedure dynamically estimates various energy balance components as detailed by Norman et al. ${ }^{69}$ During each iteration, new values of $T_{C}$ and $T_{S}$ are calculated from $T_{\text {rad }}(\theta)$ and used to estimate component sensible heat fluxes $\left(H_{C}\right.$ and $\left.H_{S}\right)$ by substituting in bulk transfer equation. The soil component of the latent heat flux $\left(\lambda E_{S}\right)$ is estimated during the progress of the iteration procedure as a residual of overall energy balance components. During each iteration, the value of component fluxes is progressively revised. When the $\lambda E_{S}$ stabilizes to a positive value the solution for component fluxes are achieved. In the case of the water-stressed condition, the value of $\lambda E_{C}$ is overestimated, which converge to a negative value of $\lambda E_{S}$. In such cases, the $\lambda E_{S}$ is set to zero, and $H_{S}$ and $H_{C}$ are recalculated. The use of the constant initial value of $\alpha_{\mathrm{PT}}$ (1.26) for all the cases of atmospheric, soil, and ground cover conditions is the major limitation of TSEB-PT approach. At advective conditions, the actual value of $\alpha_{\mathrm{PT}}$ is much higher than 1.26, which might lead to overestimation of $H .^{71}$ In order to account for varying ground cover conditions, the fractional vegetation cover, $f$ in the PT equation was modified by an empirical function of soil adjusted vegetation index. ${ }^{72}$ The influence of changing atmospheric and soil moisture conditions was addressed by a modified approach Gc-TSEB, which incorporated the canopy conductance $G_{c}$ (a function of LAI, water vapor deficit, and visible radiation) in the model to calculate the energy balance components. ${ }^{73}$

Unlike the PT approach, the PM approach requires vapor pressure deficit and canopy resistance information to execute the model. This could account for the increased transpiration rate due to advective conditions as well as for the low relative humidity cases. TSEB-PM approach estimated more accurate soil and vegetation component temperatures and showed slightly superior performance compared to the PT approach at normal conditions. ${ }^{74}$ The unavailability of air temperature and wind speed measurements for a larger area hinder the applicability of TSEB-PT and TSEB-PM approaches for larger-scale applications. When comparing the performance of PT and PM approaches, both the models showed almost similar performance with a slight upperhand for TSEB-PM. The root-mean-square error (RMSE) of estimated $H$ was 44.9 and 
$47.5 \mathrm{~W} \mathrm{~m}^{-2}$ for TSEB-PM and TSEB-PT, respectively. ${ }^{75}$ The $\lambda E T$ also showed a similar trend (TSEB-PM-70.6 $\mathrm{W} \mathrm{m}^{-2}$ and TSEB-PT-75.3 $\mathrm{W} \mathrm{m}^{-2}$ ).

TSTIM is a time-integrated iterative two-source model essentially meant for regional to continental-scale applications. ${ }^{76}$ The model is an extension of TSEB models that use two instantaneous satellite acquisitions to estimate the sensible heat flux. The two satellite observations, which are acquired just after the sunrise and before noon, reduce the effect of advection to a reasonable extent and avoid the requirement of local calibration and precise air temperature data. ${ }^{77}$ The two submodels associated with the TSTIM are surface layer component (SLC) and PBL component. The SLC follows the TSEB modeling schemes that compute instantaneous sensible heat fluxes $H_{1}$ and $H_{2}$ using radiometric temperature data at times $t_{1}$ and $t_{2}$ by assuming a linear increase in the sensible heat flux. ${ }^{78}$ The ALEXI model is a well-known time-integrated model that retrieve the surface energy fluxes at 5 to $10 \mathrm{~km}$ resolution using the two instantaneous values of sensible heat flux. ${ }^{79}$ Most of the studies related to ALEXI used the LST from GOES at a temporal resolution of 30 min or from Meteosat Second Generation (MSG) retrieved at every $15 \mathrm{~min}$. The spatial resolution of GOES and MSG are $4 \mathrm{~km}$ and $3 \mathrm{~km}$, respectively, at nadir.

\subsection{Sensible Heat Flux Estimation Approaches in Non-Iterative Two-Source ET Models}

The requirement of locally measured surface roughness length and wind speed narrowed the application potential of two-source iterative models for heterogeneous landscapes with nonlinear surface characteristics. In iterative PT and PM formulations, the ambiguity of the initializing parameters induced significant biases in the $H$ estimations. The use of directional radiometric temperature to estimate the soil and vegetation component temperatures eliminates the use of initializing parameter to estimate the canopy transpiration. The non-iterative two-source models estimate component temperatures either using simultaneous observations of directional temperatures from two viewing angles, or by surface temperature measurements from a single viewing angle. The retrieval of component temperatures by single $T_{s}$ observation is complex and requires a "VFC-LST feature space" and in situ meteorological data sets. Those models that utilize the VFC-LST feature space are classified as non-iterative feature space-based models.

\subsubsection{Non-iterative feature space-based models}

The scatter plot of VFC versus LST forms a trapezoidal or triangular space for an area with a wide range of land-use and land-cover types. The trapezoidal spectral space could adequately account for the water stress, canopy transpiration, and the aerodynamic effects of the surface compared to triangular space. ${ }^{80,81}$ The VFC-LST space-based models gained attention due to its site-independent model parameterization capability. These models decompose the $T_{\text {rad }}(\theta)$ into $T_{C}$ and $T_{S}$ using soil surface moisture availability isopleths superimposed on trapezoidal space. ${ }^{81}$ The warm edge and the cold edge of the trapezoidal space (Fig. 3) define the boundary condition for VFC-LST space-based models. There exist several isopeistic lines within these boundary conditions that represent the same soil surface moisture availability for the same $T_{S}$ values. ${ }^{82}$

One of the earlier versions of the VFC-LST space-based patch model called two-source trapezoidal model for evapotranspiration (TTME) utilizes the trapezoid framework and isopleths of soil surface moisture availability to calculate energy balance components. The $T_{s, \max }$ that defines the upper boundary conditions requires stability corrected aerodynamic resistance through an iterative process (non-iterative for estimating surface energy balance components), and the $T_{s, \text { min }}$ corresponds to the spatially averaged air temperature $\left(T_{a}\right)$. The TTME uses these boundary conditions for decomposing radiometric temperatures into soil and canopy component temperatures. These component temperatures are subsequently used for calculating component evaporation fractions. The model estimates $H$ as a residual of the energy balance equation, and the values are sensitive to the boundary conditions. ${ }^{83}$ HTEM is a modified form of TTME model that adopts a hybrid scheme of the layered and the patch approaches. The soil and vegetation components of $H$ are estimated directly using component temperatures in bulk transfer equation. The procedure for the retrieval of component temperatures is the same as that of TTME model. Both TTME and HTEM rely upon the average value of $T_{a}$, albedo, aerodynamic resistance, and 


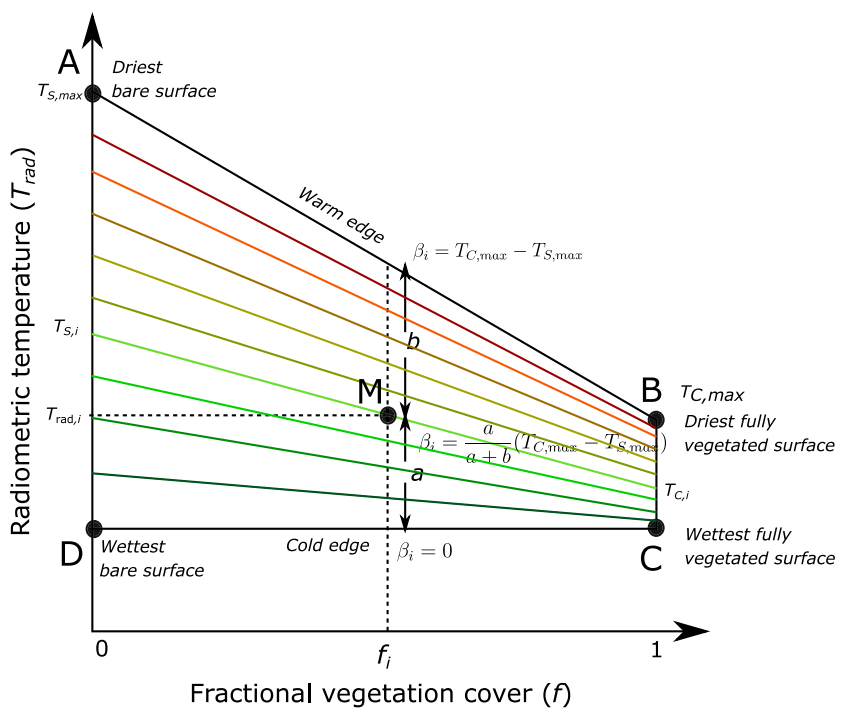

Fig. 3 VFC-LST feature space, applicable to the models such as TTME, HTEM, and ETEML.

water vapor pressure of the entire image, which may lead to the incorrect temperature transformations. ${ }^{84}$ The modified version of trapezoidal approach enhanced two-source evapotranspiration model for land (ETEML) focuses on estimating canopy-air temperature gradient $\left(T_{C}-T_{a}\right)$ and soil-air temperature gradient $\left(T_{S}-T_{a}\right)$, which eliminates the need for spatially varying air temperature. In ETEML, physically based theoretical equations define the boundary conditions rather than the empirical equations. The conventional trapezoidal space used in TTME, HTEM, and ETEML assumed to have a horizontal wet edge, which was determined by the lowest air temperature in the study area. The invalid cold edge assumption often led to the underestimation of the EF. The modified two-stage LST-VFC feature space-based, "two-source model for estimating evaporative fraction (TMEF)" succeeded this limitation by calculating the cold edge by PT equation. ${ }^{85}$ The comparison of LST-VFC space-based models revealed that the $H$ estimation of HTEM showed the least deviation (14.5\%) from reference EC measurements compared to ETEML (18\%) and TTME $(24.5 \%){ }^{83,86,87}$ In the case of $\lambda E T$, the values are $9.1 \%, 1.5 \%$, and $24.7 \%$ for HTEM, ETEML, and TTME, respectively.

\subsubsection{Non-iterative non-feature space-based models}

The directional radiometric surface temperature viewed from two different sensors can infer the canopy geometry and the vertical canopy temperature profile. It also nullifies the directional influences of $T_{S}$ while substituting for $T_{0} .{ }^{88}$ TSEB-2A showed lesser mean absolute percentage error compared to single-source iterative models $(\lambda E-15 \%$ and $H-35 \%$ from EC measurements ${ }^{89}$ ). The limited availability of sensors with simultaneous measurements in two view angles made this concept less operational. The along track scanning radiometer (ATSR) onboard ERS-1 satellite, advanced along-track scanning radiometer (AATSR) onboard Terra satellite, and ASTR-2 onboard ERS-2 were used in various studies to prove the strength of the dual view angle approach. ${ }^{90,91}$ The data from SLSTR of Sentinel-3 are a possible data source to implement the dual angular approach (refer to Table 4 in Appendix A for sensor details). The TSEB-2A calculates $T_{C}$ and $T_{S}$, by solving two simultaneous equations for radiometric surface temperature $\left(T_{\text {rad }}(\theta)=\left\{f(\theta) T_{C}^{4}+[1-f(\theta)] T_{S}^{4}\right\}^{\frac{1}{4}}\right)$ from two different view angles $\left(\theta_{1}\right.$ and $\left.\theta_{2}\right)$. The dual-angle approach eliminates the dumping of bias into $H$, as it directly calculates sensible heat flux from $T_{C}$ and $T_{S}$. The $H$ estimation is extremely sensitive to the clumping of vegetation cover, and its importance was proved in the initial trials of TSEB-2A using the airborne data collected during First International Satellite Land Surface Climatology Project (ISLSCP) Field Experiment (FIFE). ${ }^{89}$ The simplified two-source energy balance (STSEB) model is a simplified patch version of TSEB model of non-iterative class, which excludes the PT approximation and estimates the total sensible heat flux as the weighted sum of canopy and soil component fluxes at 
the field scale. STSEB is an efficient model that requires fewer input variables compared to iterative TSEB models but necessary to collect the field-measured component temperatures. ${ }^{92}$

\section{Unmanned Aerial Vehicles for Turbulent Heat Flux Estimation}

The lack of sufficient in situ data sources for the validation of ET models and the requirement of the high-resolution dataset with frequent coverage prompted the utilization of UAV techniques in the domain of surface energy budget. ${ }^{93}$ The UAVs provide economic and compact instrumentation for real-time monitoring of fluxes in precision farming. The fixed-wing UAVs are preferred over rotary wings for large-scale field applications where heavy RS cameras and micrometeorological sensors are required. The multi-spectral and thermal infrared sensors attached to the UAV platform bridge the gap in scale between the field-based and satellite-based observations. Models such as SEBAL, METRIC, and TSEB-PT have been tested for UAV applications, and the TSEBPT have exhibited better potential for UAV applications. ${ }^{94}$ These models are designed for satellite images with medium to coarse resolutions and modifications are required while using it for highresolution UAV images. The larger data volume for smaller areas demands complex algorithms to achieve better results. TSEB-2T ${ }^{95}$ and deriving atmosphere turbulent transport useful to dummies using temperature (DATTUTDUT) $)^{96,97}$ are the two models that suit better for UAV applications. The TSEB-2T model employs contextual $T_{\text {rad }}$-NDVI space to estimate the soil and vegetation component temperatures. The model identifies pure pixels of vegetation and soil from the high-resolution images for the estimation of $T_{S}$ and $T_{C}$. In contrast to contextual models, DATTUTDUT model estimates EF solely from surface temperature information. The small multi-function research and teaching Sonde application proved the reliability of temperature and humidity measurements from UAV platforms for the estimation of sensible heat flux. ${ }^{98,99}$ Another recent research related to surface flux estimations revealed that the wind speed, temperature, and relative humidity from UAVs were in good agreement with ground-based values and the data quality was sufficient for the computation of the bulk heat transfer coefficient. ${ }^{100}$

\section{LST and ET Models}

The accurate estimation of LST is crucial in RS-based ET models due to its importance as a boundary condition. The first ISLSCP-FIFE reported an error of up to $100 \mathrm{wm}^{-2}$ for instantaneous $H$ measurements due to variations in measured thermal infrared measurements. ${ }^{101}$ The appropriate calibration and atmospheric correction of satellite-based thermal infrared observations are essential to minimize these errors. ${ }^{102}$ Due to the complexities and cost of the technology, there are very few operational satellites with thermal bands available to the user community (refer to Table 4 in Appendix A for sensor details).

\subsection{Thermal Remote Sensing Missions}

The history of thermal RS related to ET models traces back to 1962 with the launch of TIROS-II. During the early 1970s, the aerial RS was the only mode of getting thermal images for understanding agricultural crop stress. The launch of GOES (in 1975) and NOAA/AVHRR (in 1979) satellites with thermal sensors became the significant milestones toward the use of satellite RS technology for surface energy balance studies. These missions delivered thermal images with a high temporal resolution (daily) and coarse spatial resolution $(1 \mathrm{~km})$. Landsat 5 mission (1985) was the first mission that collected thermal images with a relatively high spatial resolution $(120 \mathrm{~m})$ at the cost of its temporal resolution (16 days). Terra (1999) and Aqua (2002) missions with MODIS were of the same category as that of AVHRR, in spatial and temporal resolution, but with a large number of optical and infrared bands that could collect vegetation- and soilrelated information along with thermal bands. Suomi NPP or JPSS-1 (2011) with VIIRS sensor improved the spatial resolution to $750 \mathrm{~m}$ keeping the daily temporal resolution. ERS-1 (1991) and ERS-2 (1995) satellites delivered thermal images of the same area from two view angles in tandem to facilitate the development of two-source ET models. The collection of thermal images with a high spatial and temporal resolution was a challenge for both polar and geostationary 
satellites. Use of two polar-orbiting satellites (Landsat) in tandem was a solution to this problem but constrained to the radiometric quality of the data due to two different sensors. ECOSTRESS mission is a new solution to the problem mentioned above, where the thermal scanner is onboard International Space Station, which would deliver thermal images with high spatial $(69 \mathrm{~m})$ and temporal (daily) resolution. ECOSTRESS is a unique mission where the users are provided with ready-made ET maps in 30-m resolution using ALEXI and PT-JPL (Priestley-Taylor Jet Propulsion Laboratory) algorithm. The latest version of ECOSTRESS is expected in 2020 or 2021. There are missions such as HyspIRI and TRISHNA in the conceptual and planning stage that could deliver similar products with high spatial and temporal resolution. Refer to Table 3 for a comprehensive list of operational and future thermal RS missions.

\subsection{Data Assimilation Approaches}

The two major approaches based on the use of LST for the estimation of turbulent heat fluxes are the diagnostic/retrieval-based approach and DA approach. ${ }^{103}$ The retrieval approach mainly focuses on instantaneous heat flux estimations from satellite images, and a variety of empirical and physical models discussed in this review comes under this category. The retrieval methods estimate the turbulent heat fluxes only for the available instances of LST observations. In contrast, the assimilation techniques capture the significant amount of information contained in the temporal datasets of LST and estimate the turbulent heat fluxes for instances without LST observations. ${ }^{104}$ The recent research in the field of DA techniques yielded numerous techniques that are mainly grouped into variational data assimilation (VDA) techniques and ensemble techniques. VDA techniques utilize the force-restore equation or full heat diffusion equation to predict LST by assimilating the known instances. By minimizing the difference between the RS derived LST and predicted LST, the optimum values of the unknown neutral bulk heat transfer coefficient $\left(C_{\mathrm{HN}}\right)$ and $\mathrm{EF}$ are estimated. The $C_{\mathrm{HN}}$ is a function of changing phenology that varies monthly, whereas the EF changes daily, and it is affected by soil moisture and LAI. The $C_{\mathrm{HN}}$ scales the sum of turbulent heat fluxes, and EF scales the partitioning of turbulent heat fluxes. ${ }^{105}$ Among single-source and two-source VDA schemes, the performance of two sources is comparatively better due to the differences in cost functions for minimizing the observed and predicted LST. ${ }^{103}$ The VDA approach performed better for sparse vegetated dry regions compared to dense vegetated wet areas. The incorporation of daily precipitation as forcing input improved the results in wet areas. ${ }^{106}$ The main limitation of VDA is that it does not consider the mutual influence of water and energy in the soil plant atmosphere continuum. Therefore, soil moisture assimilation has a powerful influence on the improvement in heat flux predictions. ${ }^{107}$ When using predicted LST in surface energy balance models, the uncertainties in $H$ estimation by VDA schemes are mainly due to errors in the $C_{\mathrm{HN}}$ and LST estimates. Similarly, the uncertainties in $\lambda E T$ are influenced by $\mathrm{EF}, C_{\mathrm{HN}}$, and LST measurements. ${ }^{103}$

The ensemble Kalman filter (EnKF) and ensemble Kalman smoother (EnKS) are the two approaches that became better choices compared to the VDA approach. The ensemble approaches are efficient due to their easy formulation, non-linear capture, the ability to account for a wide range of measurement errors, and their capability to provide uncertainty estimates. ${ }^{108}$ The EnKF and EnKS mainly differ in their selection of inputs for the prediction process. In the EnKF, the prediction for a time $t$ considers all available observations prior to and at time $t$, whereas in EnKS the observations that are available prior to and subsequent to the time $t$ are used. The critical parameters related to the surface control and surface turbulence in ensemble methods are the same as that of the VDA approach (i.e., $C_{\mathrm{HN}}$ and $\mathrm{EF}$ ), but estimated by a different approach called "state augmentation method." The $H$ and $\lambda E T$ estimates from the EnKS scheme revealed that the uncertainty of the estimated $H$ is related to the errors in EF, $C_{\mathrm{HN}}$, incoming solar radiation, and air temperature. Similarly, the uncertainty of $\lambda E T$ depends only on the predicted $H$ and EF. ${ }^{108}$

\section{Influence of Scale Effects and Validation of ET Models}

Validation and comparison of ET models have been conducted across the world in various climatic zones by methods such as the Bowen ratio, lysimeters, EC system, and large aperture 
scintillometers. (refer Tables 1 and 2). It is essential to compare the performance of models by maintaining similar site conditions, sensor and field validation method. Adhering to these, this review compared the research outcomes of popular ET models at SMACEX site (MoistureAtmosphere Coupling Experiment in central Iowa) and HiWATER-MUSOEXE site (Heihe Watershed Allied Telemetry Experimental Research in China) for various studies conducted between 2006 and 2018 (refer to Fig. 4). The SMACEX $\left(41.87^{\circ} \mathrm{N}\right.$ to $42.05^{\circ} \mathrm{N}, 93.83^{\circ} \mathrm{W}$ to 93.39 $\mathrm{W})$ and HiWATER-MUSOEXE $\left(41.87^{\circ} \mathrm{N}\right.$ to $42.05^{\circ} \mathrm{N}, 93.83^{\circ} \mathrm{W}$ to $\left.93.39^{\circ} \mathrm{W}\right)$ fall under hot summer continental climate and cold desert climate, respectively. For SMACEX and MUSOEXE sites, satellite data from ETM+ and ASTER, respectively, were considered for comparison. The comparison based on RMSE and bias of $\lambda E T$ and $H$ showed that the VFCLST feature space-based model HTEM exhibited an overall better performance, followed by TTME and ETEML for both the sites. Among single-source models compared at SMACEX sites, the SEBAL showed better performance statistics compared to SEBS and METRIC, and the same results were obtained in a site nearby Oklahoma using OLI/TIRS data. ${ }^{130}$ The superior performance of SEBAL could not be generalized for all the ground cover conditions and climatic zones. $^{30}$

The validation of the surface energy balance models depends on the spatial resolution of its outputs. ${ }^{131}$ The approach for validation of fine-resolution products is generally straightforward due to its scale correspondence with the ground measurements. For coarser-resolution products (>100 m, e.g., MODIS), the already validated fine-resolution products are used after up-scaling or aggregation. ${ }^{132}$ The methods such as simple averaging, nearest neighbor sampling, bilinear interpolation, or bicubic interpolation are the usual techniques used in the aggregation process. The aggregation of the input bands of the ET models or the aggregation of its fine resolution outputs (fluxes) are the two main aggregation approaches. The effect of aggregation varies with models as well as the resolution to which the aggregation is targeted. A study conducted on the aggregation of RS images from $5 \mathrm{~m}$ (very high resolution) to $1 \mathrm{~km}$ and its impact on surface energy balance components revealed that at spatial resolutions $<30 \mathrm{~m}$ the difference in $H$ values were negligible (2\%) and it increased up to $24 \%$ at lower spatial resolutions. ${ }^{133}$ This could be due to the impact of aggregation on the actual values of NDVI and $T_{s}$, and calibration pixels, which could influence the values of estimated $H$. Scaling can affect the values of aerodynamic resistance, calculated empirically from vegetation indices. In SEBS, the input aggregation approach using a simple average of the pixel within a kernel window performed better in preserving the magnitude and the spatial distribution of fluxes. Contrary to this, the simple averaging procedure exhibited inferior performance in the case of flux aggregation. ${ }^{134}$ However, in the case of SEBAL, both the input and output aggregation showed similar spatial patterns. ${ }^{135}$ In the case of METRIC, the sensible heat flux exhibited higher sensitivity to the aggregation process than the latent heat flux due to the non-linear changes of surface roughness parameters in the model. ${ }^{133}$ In the VFC-LST feature space-based ET models, the aggregation process has a considerable impact on the shape of the trapezoidal scatter plot, which would change the boundary conditions for ET estimation. The other components $R_{n}$ and $G$ are relatively insensitive to the changes in spatial scales owing to the fact that these parameters are calculated from incoming solar radiation whose spatial variability is not intensive as in the case of vegetation and soil parameters. ${ }^{136}$ One of the main factors that hinder the scaling up of the popular RS-based ET models is the need of in situ air temperature data and wind speed data for the estimation of $H$. Though the single-source models such as METRIC and SEBAL avoided the use of near-surface air temperature by adopting $d T$ approach, the requirement of $u$ for the stability correction restricted its applications beyond the regional scale. Similarly, the dependence of TSEB-PT model on the in situ air temperature values limits its scalability for larger areas. In cases where the in situ air temperature data are unavailable, the capability of ALEXI to calculate $T_{a}$ internally was utilized to estimate higher resolution turbulent heat fluxes. This is achieved by ALEXI flux disaggregation approach popularly known as DisALEXI. ${ }^{119}$ Though the disaggregation of ALEXI was proved to be efficient in estimating fluxes, the demand for computationally simple and disaggregation free method resulted in the TSEB-I method. The TSEB-I is a hybrid of single- and two-source approaches that estimates $T_{a}$ by combining the self-calibration concept of SEBAL and the physically based land surface representation of TSEB. The air temperature was estimated using the cold pixel in the study area by sensible heat flux inversion 
Mohan, Kanchirapuzha, and Varma: Review of approaches for the estimation of sensible heat flux...

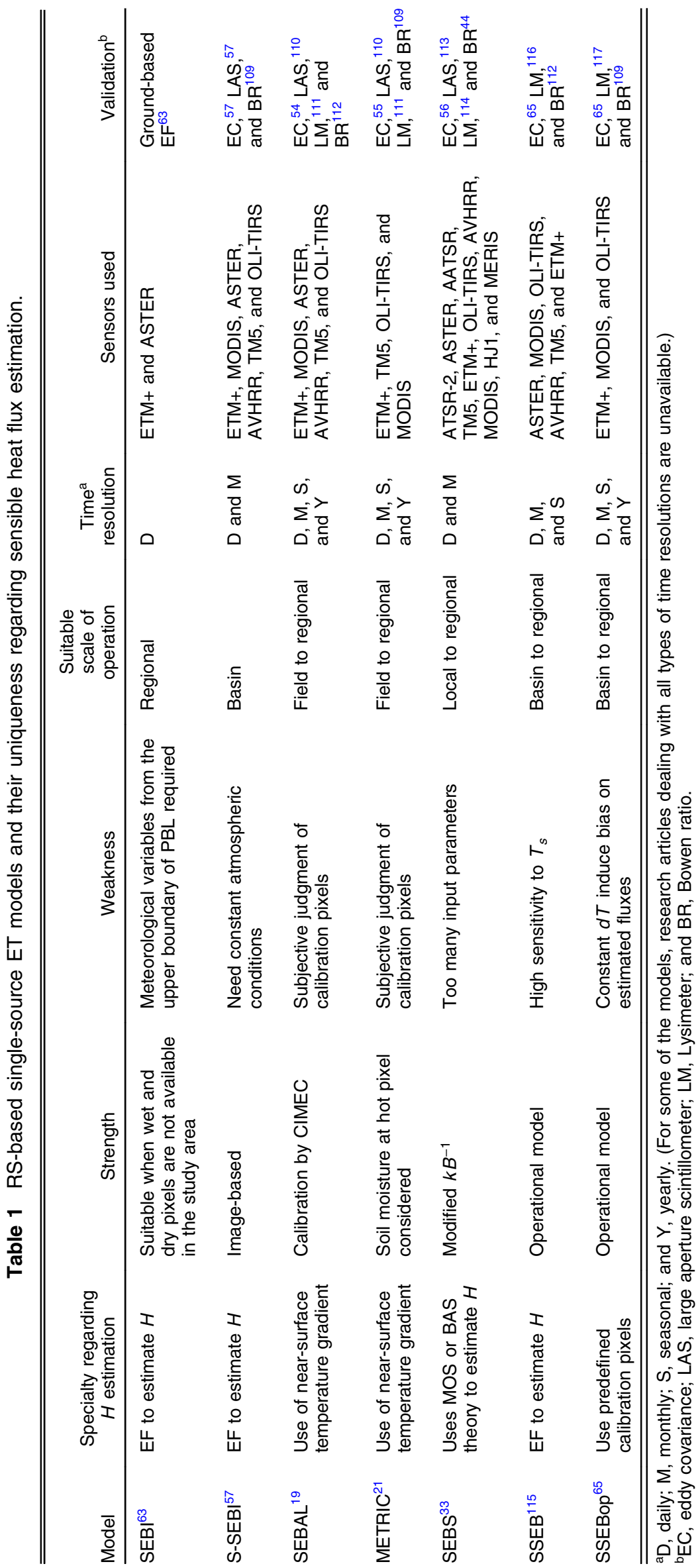


Mohan, Kanchirapuzha, and Varma: Review of approaches for the estimation of sensible heat flux...

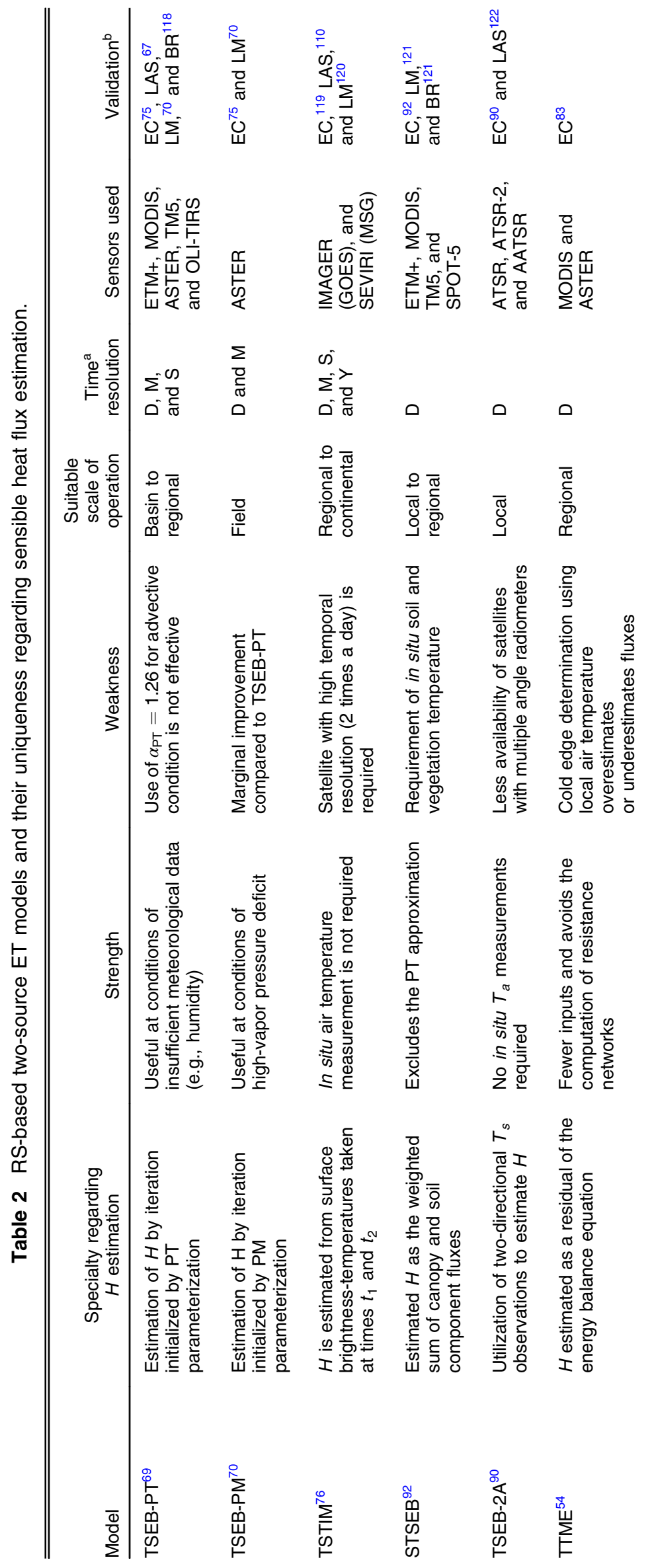


Mohan, Kanchirapuzha, and Varma: Review of approaches for the estimation of sensible heat flux...

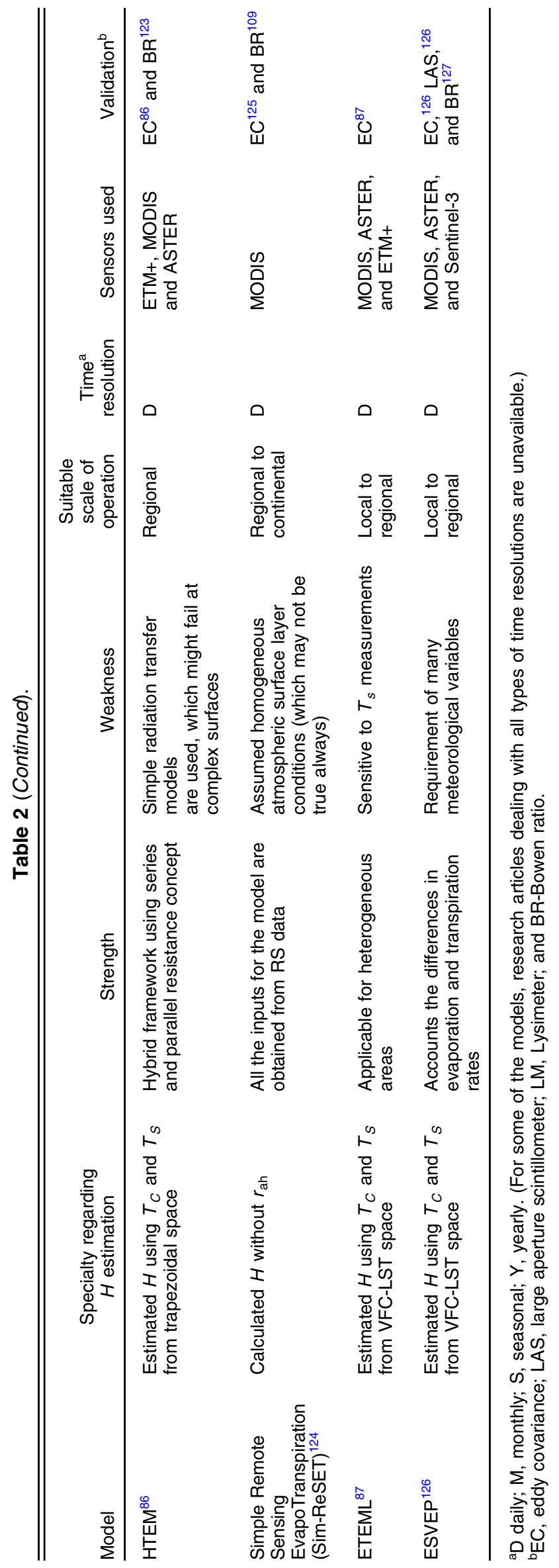



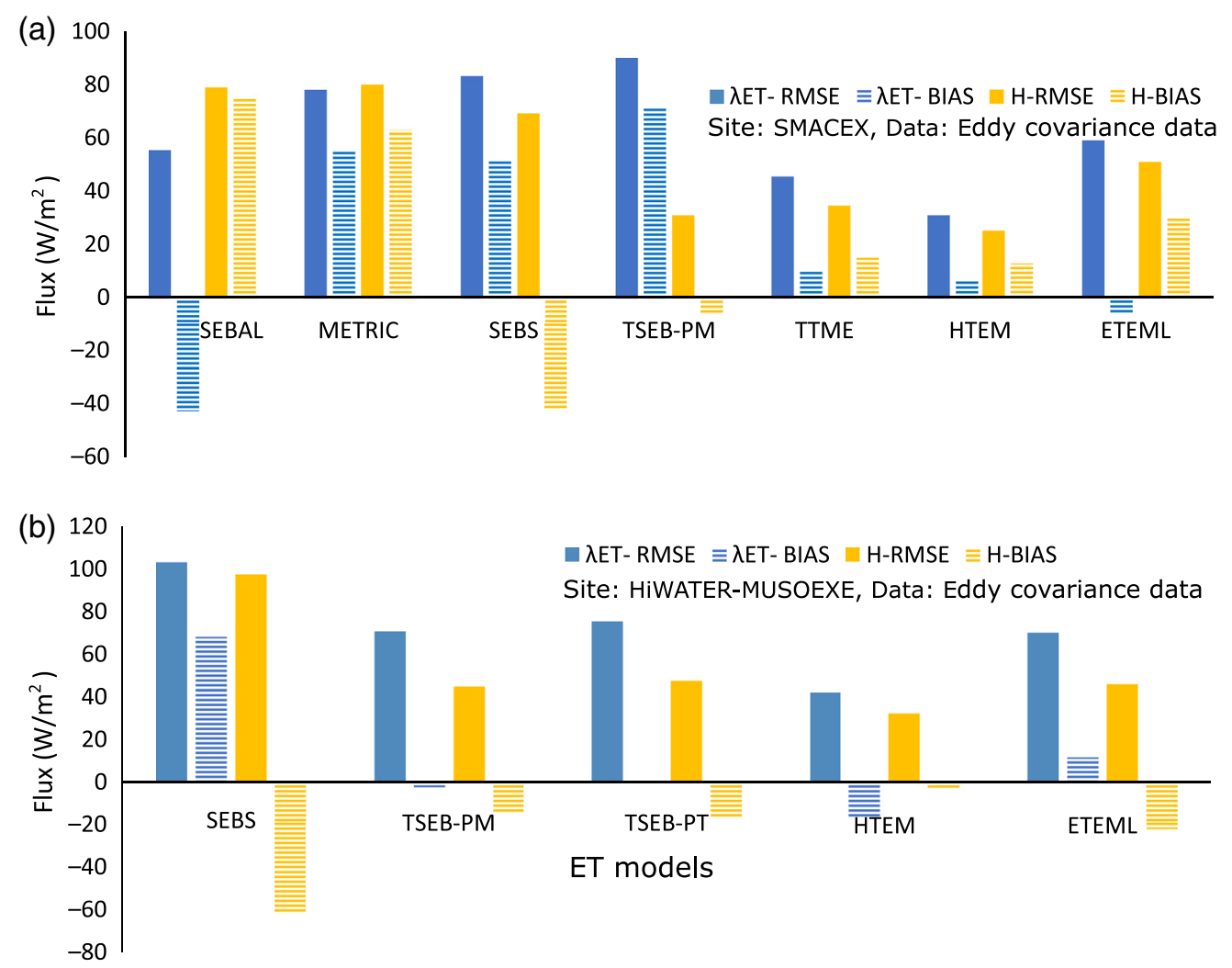

Fig. 4 (a) Comparison of RS-based ET models using SMACEX data (SEBAL, ${ }^{54}$ METRIC, ${ }^{55}$ SEBS, ${ }^{128}$ TSEB-PM, ${ }^{55}$ TTME, ${ }^{83} \mathrm{HTEM}^{86}$ and ETEML ${ }^{87}$ ) and (b) comparison of RS-based ET models using HiWATER-MUSOEXE data (SEBS, ${ }^{56}$ TSEB-PM, ${ }^{75}$ TSEB-PT, ${ }^{75}$ HTEM, ${ }^{75}$ and ETEML ${ }^{129}$ ).

method. ${ }^{137}$ A study conducted using DisALEXI, TSEB-I, and TSEB-PT revealed that the estimated air temperature showed an average difference in the order of $1 \mathrm{~K}$ only. ${ }^{137}$ Similarly, the need for spatially varying air temperature restricts the HTEM to scale its application from field to regional scales. By coupling with a simple time-integrated ABL model, the modified HTEM was able to perform better than its basic version and the RMSE was found to be $<1 \mathrm{~mm} \mathrm{~d}^{-1}$. The estimated value of $T_{a}$, by HTEM-ABL, was in close agreement with the in situ measured values. ${ }^{138}$ The research outcomes revealed that the architecture of a model free from in situ $T_{a}$ measurement might not ultimately contribute to its scalability. The best instance is TSEB-PT, where the use of simultaneous directional radiometric temperatures could alleviate the need of $T_{a}$ but its greater dependency on in situ wind speed disable the model for largerscale applications. A simple temperature domain two-source model (TD-TSEB) is a model that does not use wind speed measurements to estimate sensible heat flux, but it requires in situ $T_{a}$ as an input parameter. The moderate sensitivity of TSEB-TD to $T_{a}$ values promoted its successful application for larger river basins. ${ }^{139}$

\subsection{Milestones}

This review recapitulates the essential milestones of research and developments in the domain of sensible heat flux estimation through RS-based methods (Table 4 in Appendix A) for the last 120 years. The events are selected based on the contribution of research outcomes for further research associated with sensible heat flux. The milestones facilitate to categorize the research period into different focal periods of development. Till 1970, most of the research focussed on fundamental research related to micrometeorology, plant physiology, and its relation to ET, canopy temperature, and aerodynamic resistance. The RS-based ET estimation attained more 
importance between 1970 and 1990 due to the accelerated developments in the satellite RS technology. The evolution of the thermal imaging sensors and their capability to estimate LST has revolutionized the RS-based ET research. The period after 1990 till 2019 was the period of "RS-based ET models," during which many single-source and two-source models were proposed and validated.

\subsection{Current Research Activities}

Though the two-source models are gaining more attention within the research community, the single-source models still continue to contribute through rigorous revisions for the last 10 years. Among the single-source models, SEBS, SEBAL, and METRIC are mainly modified intensively. In SEBS, the research activities are mainly focussed on the incorporation of the soil moisture information into the model for the improvement of the accuracy of $H$ estimation. The domain of the anchor pixel selection process and its automation are the primary focus in the case of SEBAL and METRIC. In TSEB models, the non-iterative VFC-LST space-based models are getting more attention due to its simplicity and better performance. Current research activities focus on delineating VFC-LST space boundaries appropriately. In two-source iterative models, the research mainly focused on the value of $\alpha_{\mathrm{PT}}$, which is an initialization parameter for the iteration process. Between the years of 1990 and 2020 (period of RS-based ET models), the main research focus was to improve the parameterization of roughness lengths, aerodynamic resistance, canopy resistance, and soil resistance. Statistics of the research activities for the last 10 years revealed that the parameterization of roughness length and aerodynamic resistance was the central area of research (Fig. 5). The application of UAV images in the context of turbulent heat flux estimation is one of the primary focus of the current area of research. There is an accelerated development in the UAV hardware and related algorithms in order to facilitate the transition of the ET models to replace satellite images with UAV products. The near real-time monitoring of ET is the need of the time by utilizing the UAV outputs as better inputs to twosource models such as TSEB-PT, TSEB-PM, and TSTIM. Field crop-based calibration of the models based on leaf area index or canopy height and growth stages makes the RS-based ET domain more crop and field-specific. The application of UAV images in the context of turbulent heat flux estimation need to be refined further by alleviating the challenges, which include the radiometric accuracy of thermal images attributed to low signal-to-noise ratio, camera noise, interimage sensor noise, and atmospheric conditions. ${ }^{140}$ The existing surface energy balance models rely mainly upon optical dataset for retrieving the parameters of the model either direct or in the indirect form and the potential of SAR dataset such as ESAs Sentinel-1A/1B with 6 days of temporal resolution is less explored. Its high spatial $(20 \mathrm{~m})$ and temporal resolution (6 days) make the mission suitable for exploring the possibilities of retrieving crop structural parameters and soil moisture that can be incorporated in the ET models. The thermal data with a high temporal and spatial resolution for surface energy balance models are an ideal requirement,

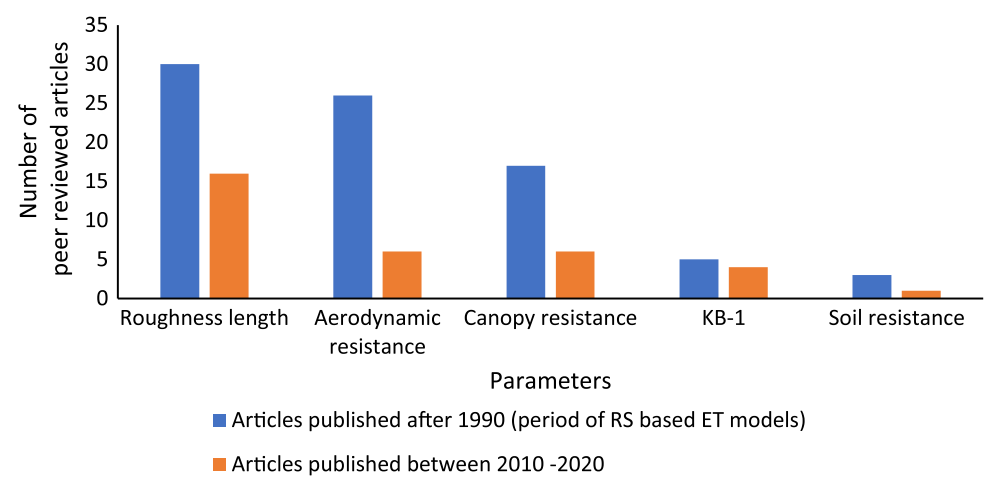

Fig. 5 Thrust area of research between 1990 and 2020. Prepared using the data collected from Ref. 31. 
and the possibility of disaggregating of MODIS LST using SAR data and Landsat 8 data is being explored. ${ }^{141}$

\section{Current Challenges and Perspectives}

The synapse between the challenges and the developments of RS-based $H$ estimation techniques witnessed various facets of improvisations cornered mainly to the refinement of the architecture of classical ET models. The unwrapping of challenges of most of the RS-based models knocks at the role of the multitude of variant parameters that significantly contribute toward the robust model architecture. This review attempted to identify the prominent challenges related to the RS-based sensible heat flux estimation approaches using the insights obtained through the research outcomes across the globe. This review tried to address minor challenges related to each model along with model descriptions. The challenges listed below focussed entirely on the current thrust area of research related to turbulent heat flux estimations using RS-based ET models.

- To modify the VFC-LST feature space-based models for ecosystems where the LST and $V F C$ are positively correlated. The assumption of the inverse relationship between LST and VFC in trapezoidal feature space-based models will not be valid for all types of ecosystems. At mid- and high-latitude regions (forest steppe ecosystem, high mountains, and taiga), the increase in vegetation growth is proportional to the increase in temperature. ${ }^{142}$ At such conditions, the geometry of the trapezoidal space changes and the approaches for the retrieval of boundary conditions to be modified.

- To incorporate a dynamic PT coefficient instead of a fixed value of 1.26 in RS-based TSEB-PT model for the initialization of iteration. The fixed value of 1.26 applies to saturated conditions and vary with a multitude of parameters such as soil water stress, vapor pressure deficit, VFC, air temperature, and ground cover conditions. ${ }^{143}$ The TSEB model did not account the changes in the vapor pressure deficit and stomatal conductance in the model formulation leading to higher $T_{C}$ and lesser $H$. Though the modified approach TSEB-PM has made a slight improvement in terms of RMSE of estimated flux, the night time ET by both the models showed negative values (not always). ${ }^{74}$ The TSEB-PT consistently showed this error and modification by a dynamic PT coefficient might address this limitation.

- To modify the TSEB-2A model using satellite-based multi-angular thermal observations. Using airborne data, the TSEB-multi-angular model was successfully implemented for heterogeneous land surface conditions, which revealed its superior performance compared to TSEB-2A model. ${ }^{89}$ The multi-angular implementation requires new satellite missions that could procure more than two thermal images simultaneously.

- To incorporate downscaled soil moisture products into ET models to enhance turbulent heat flux estimations. The spatial resolution available for soil moisture active passive mission (SMAP) is 30 to $40 \mathrm{~km}$ with a volumetric accuracy of $0.04 \mathrm{~m}^{3} \mathrm{~m}^{-3}$ in the top $5-\mathrm{cm}$ soil layer, covered with moderately thick vegetation with canopy moisture content $<5 \mathrm{~kg} \mathrm{~m}^{-3}$. ${ }^{144}$ The feasibility of downscaling soil moisture products to 1 - to 5 -km resolution using thermal bands of MODIS or Sentinel-3, is to be checked in future studies to support regional to continental scale ET estimations. There are successful attempts reported in achieving soil moisture products at $10-\mathrm{km}$ resolution using the synergy of SMAP, AMSR2, and Sentinel-1 datasets. ${ }^{145}$ The soil moisture products obtained by downscaling could be used to derive surface energy balance components for all-weather conditions.

- Need for thermal remote sensing missions with high spatial and temporal resolutions. The need for increased cloud-free observations with the high spatial and temporal resolution is essential to estimate crop water requirements daily or weekly basis. The current thermal RS missions deliver thermal data with moderate resolutions at the cost of poor temporal resolutions. The future missions such as ECOSTRESS (new version), HysPIRI, and TRISHNA are promising thermal RS ventures that would provide better datasets for ET models. Refer to Table 3 for future thermal RS missions by various space agencies. Details of operational thermal RS missions are included in Table 4 in Appendix A. 
Mohan, Kanchirapuzha, and Varma: Review of approaches for the estimation of sensible heat flux...

Table 3 Details of operational and future satellite missions with thermal infrared sensors

\begin{tabular}{|c|c|c|c|c|c|}
\hline Sensor ${ }^{a}$ & $\begin{array}{l}\text { Satellite or } \\
\text { payload }\end{array}$ & Launch (year) & $\begin{array}{l}\text { Revisit } \\
\text { (days) }\end{array}$ & $\begin{array}{l}\text { Resolution }^{b} \\
(\mathrm{~m})\end{array}$ & $\begin{array}{l}\text { Space } \\
\text { agency }\end{array}$ \\
\hline \multicolumn{6}{|l|}{ Future missions } \\
\hline TIRS-2 & Landsat-9 & 2020 & 16 & 100 & NASA \\
\hline ECOSTRESS & ISS & Post-2020 & 3 to 5 & 69 & NASA \\
\hline $\mathrm{FCl}$ & MTG & 2021 & Daily & 2000 & TAS France \\
\hline SLSTR & Sentinel-3C & 1000 & Daily & 2021 & ESA \\
\hline VIIRS & JPSS-2 & Post-2021 & Daily & 750 & NASA \\
\hline SLSTR & Sentinel-3D & Post-2021 & Daily & 1000 & ESA \\
\hline HyspIRI SBG & Conceptual & Post-2023 & 5 & 60 & NASA \\
\hline TRISHNA & (Feasibility stage) & Post-2024 & 3 & 50 & $\begin{array}{l}\text { ISRO and } \\
\text { CNES }\end{array}$ \\
\hline VIIRS & JPSS-3 & Post-2026 & Daily & 750 & NASA \\
\hline VIIRS & JPSS-4 & Post-2031 & Daily & 750 & NASA \\
\hline \multicolumn{6}{|c|}{ Operational missions } \\
\hline ETM+ & Landsat 7 & 1999 & 16 & 60 & NASA \\
\hline MODIS & Terra and Aqua & 1999 and 2002 & 16 & 1000 & NASA \\
\hline SEVIRI & Meteosat-8, 9, 10, 11 & $\begin{array}{l}2002,2005,2012 \\
\text { and } 2015\end{array}$ & Daily & 3000 & ESA \\
\hline AVHRR & NOAA-18, 19 & 2005 and 2009 & Daily & 1000 & NASA \\
\hline AVHRR/3 & Metop-A, B, C & $2006,2012,2018$ & Daily & 1000 & ESA \\
\hline TIRS & Landsat-8 & 2013 & 16 & 100 & NASA \\
\hline VIIRS & Suomi NPP, JPSS-1 & 2011 and 2017 & Daily & 750 & ESA \\
\hline $\mathrm{AHI}$ & Himawari-8, 9 & 2015 and 2016 & Daily & 2000 & JAXA \\
\hline $\mathrm{ABI}$ & GOES-16, 17 & 2016 and 2018 & Daily & 2000 & NASA \\
\hline SLSTR & Sentinel-3A, 3B & 2016 and 2018 & Daily & 1000 & ESA \\
\hline ECOSTRESS & ISS & 2018 & Daily & 69 & NASA \\
\hline
\end{tabular}

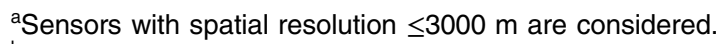

${ }^{b}$ Spatial resolution of thermal bands.

\section{Conclusions}

The current review spans across the research conducted to date in the area of sensible heat flux computations using RS-based ET models. The evolution of new-generation surface energy balance models for turbulent flux estimation, integrated with satellite sensor advances in the field of environmental RS, were discussed in the review, citing the milestones of developments starting from classical PM equation. The conceptual framework of classical models that triggered and accelerated the development of RS-based sensible heat flux models are emphasized in the beginning sections. The relevant research outcomes of each model were analyzed and summarized the essential characteristics related to sensible heat flux estimation in Tables 1 and 2. Spatial distribution of the sites where each model was executed is mapped based on the published articles under each model. It aids in the comprehensive understanding of climatic zones, in which the models are being tested. A simple classification scheme for the RS-based ET models was proposed based on the different approaches followed for the sensible heat flux estimation as iterative 
Mohan, Kanchirapuzha, and Varma: Review of approaches for the estimation of sensible heat flux...

and non-iterative categories. This review also discussed the role of advance RS techniques such as UAVs and the DA techniques under the purview of turbulent heat flux estimations in ET models. The ET models tested at SMACEX and HiWATER-MUSOEXE sites revealed that the two-source feature space-based model, HTEM performed better compared to all other models.

\section{Appendix A: Milestones}

Table 4 presents the chronological order of research and developments in the domain of sensible heat flux estimation with emphasize on the remote sensing techniques.

Table 4 Milestones of research activities related to sensible heat flux estimation.

\begin{tabular}{|c|c|}
\hline Year & Key research contributions \\
\hline 1900 & Concept of resistance for explaining the diffusion of water vapor from leaves ${ }^{5}$ \\
\hline 1921 & $\begin{array}{l}\text { The wind speed, the water surface temperature, the eddy diffusivity, distribution of water vapor above } \\
\text { the surface, and their effect on evaporation was analyzed }{ }^{146}\end{array}$ \\
\hline 1930 & The main driving factor for fluctuations in evaporation is the mean air temperature ${ }^{147}$ \\
\hline 1940 & The main resistance to evaporation from a surface is due to a thin layer of air just above the surface ${ }^{148}$ \\
\hline 1948 & Penman's equation ${ }^{1}$ \\
\hline 1951 & Big-leaf model ${ }^{149}$ \\
\hline 1954 & Experimental validation of $\mathrm{MO}$ similarity theory ${ }^{150}$ \\
\hline 1956 & Modified Penman's equation by adding stability correction ${ }^{151}$ \\
\hline 1960 & Aerodynamic resistance could be calculated from wind speed and surface resistance ${ }^{152}$ \\
\hline 1960 & The actual source/sink for mass, heat, and momentum are located at different levels ${ }^{153}$ \\
\hline 1962 & Radiometric temperature and the air temperature difference is used for estimating $\mathrm{ET}^{154}$ \\
\hline 1962 & Leaf temperature and its relation with transpiration was studied ${ }^{155}$ \\
\hline 1962 & Surface temperature from meteorological satellite TIROS-II 156 \\
\hline 1968 & $k B^{-1}$ parameter $^{8}$ \\
\hline 1970 & Flux gradient relationship for momentum readdressed (Businger-Dyer concept) ${ }^{157}$ \\
\hline 1970 & Formulation of Universal functions $\psi$ for heat and mass transfer ${ }^{25}$ \\
\hline 1972 & The areal thermal scanner was used to understand water stress in cotton canopies ${ }^{158}$ \\
\hline 1972 & Priestley and Taylor equation ${ }^{159}$ \\
\hline 1975 & Launched GOES-1. GOES continuity missions continue to produce LST images \\
\hline 1976 & The areal thermal scanner used for estimating $\mathrm{ET}^{160}$ \\
\hline 1977 & ET is linearly related to the difference between the air and the leaf temperature ${ }^{22}$ \\
\hline 1978 & Heat Capacity Mapping Mission data was used for evaporation mapping ${ }^{161}$ \\
\hline 1979 & Start of NOAA-AVHRR missions \\
\hline 1985 & Landsat-5 mission (thermal sensor: TM, spatial resolution 120 m, and revisit: 16 days) \\
\hline 1985 & Shuttleworth and Wallace's model was developed ${ }^{10}$ \\
\hline 1985 & AVHRR data were used to show the importance of vegetation height and density ${ }^{162}$ \\
\hline
\end{tabular}


Mohan, Kanchirapuzha, and Varma: Review of approaches for the estimation of sensible heat flux...

Table 4 (Continued).

\begin{tabular}{|c|c|}
\hline Year & Key research contributions \\
\hline 1986 & Concept of blending height ${ }^{163}$ \\
\hline 1987 & The formal theoretical base for ET estimation by RS of surface temperature ${ }^{164}$ \\
\hline 1989 & $E F$, remained stable during daylight hours ${ }^{165}$ \\
\hline 1991 & ERS-1 mission (thermal sensor: ASTR-1, spatial resolution $1000 \mathrm{~m}$, and revisit: 2 to 3 days) \\
\hline 1993 & $\mathrm{SEBI} \mathrm{C}^{63}$ \\
\hline 1995 & ERS-2 mission (thermal sensor: ASTR-2, spatial resolution $1000 \mathrm{~m}$, and revisit: 2 to 3 days) \\
\hline 1995 & TSEB-PT 69 \\
\hline 1997 & Two source approach by two radiometric temperature observations (TSEB-2A) ${ }^{90}$ \\
\hline 1997 & TSTIM $^{76}$ \\
\hline 1998 & SEBAL $^{19}$ \\
\hline 1999 & Massman's model for estimating $k B^{-1166}$ \\
\hline 1999 & Landsat-7 mission (thermal sensor: ETM+, spatial resolution $60 \mathrm{~m}$, and revisit: 16 days) \\
\hline 1999 & $\begin{array}{l}\text { Terra satellite (thermal sensor: MODIS, spatial resolution } 1000 \mathrm{~m} \text {, and revisit: } 1 \text { to } 2 \text { days) (thermal } \\
\text { sensor: ASTER, spatial resolution } 90 \mathrm{~m} \text {, and revisit: } 16 \text { days) }\end{array}$ \\
\hline 2000 & S-SEBI $\left.\right|^{57}$ \\
\hline 2002 & ENVISAT satellite (thermal sensor: AATSR, spatial resolution $1000 \mathrm{~m}$, and revisit: 35 days) \\
\hline 2002 & AQUA satellite (thermal sensor: MODIS, spatial resolution $1000 \mathrm{~m}$, and revisit: 1 to 2 days) \\
\hline 2002 & Meteosat-8 (thermal sensor: SEVIRI, spatial resolution 3000 m, and revisit: daily) \\
\hline 2002 & SEBS ${ }^{33}$ \\
\hline 2005 & MTSAT-1R or Himawari-6 (thermal sensor: JAMI, spatial resolution 2000 m, and revisit: daily) \\
\hline 2005 & Pixel component arranging and comparing algorithm ${ }^{167}$ \\
\hline 2005 & ET mapping algorithm ${ }^{168}$ \\
\hline 2006 & Metop-A (thermal sensor: AVHRR/3, spatial resolution 2000 m, and revisit: daily) \\
\hline 2007 & METRIC model ${ }^{21}$ \\
\hline 2008 & HJ 1B satellite (thermal sensor: IRMSS, spatial resolution $300 \mathrm{~m}$, and revisit: 4 days) \\
\hline 2009 & STSEB $^{92}$ \\
\hline 2009 & Sim-ReSET estimation ${ }^{124}$ \\
\hline 2011 & SNPP (thermal sensor: VIIRS, spatial resolution $750 \mathrm{~m}$, and revisit: daily) \\
\hline 2012 & TSEB-PM ${ }^{70}$ \\
\hline 2012 & TTME $^{54}$ \\
\hline 2013 & Landsat 8 mission (thermal sensor: TIRS, spatial resolution 100 m, and revisit: 16 days) \\
\hline 2013 & HTEM $^{86}$ \\
\hline 2014 & CBERS-4 satellite (thermal sensor: IRSCAM-4, spatial resolution $80 \mathrm{~m}$, and revisit: 26 days) \\
\hline 2015 & ETEML $^{87}$ \\
\hline 2016 & GOES-16 satellite (thermal sensor: ABI, spatial resolution 2000 m, and revisit: daily) \\
\hline
\end{tabular}


Table 4 (Continued).

\begin{tabular}{ll}
\hline \hline Year & \multicolumn{1}{c}{ Key research contributions } \\
\hline 2016 & Sentinel-3A satellite (thermal sensor: SLSTR, spatial resolution $1000 \mathrm{~m}$, and revisit: daily) \\
2016 & Soil plant atmosphere and RS ET \\
2016 & Backward-averaged iterative two-source surface temperature and energy $^{170}$ balance solution $^{170}$ \\
2016 & TMEF $^{85}$ \\
2016 & NOAA-20 or JPSS-1 (thermal sensor: VIIRS, spatial resolution $750 \mathrm{~m}$, and revisit: daily) \\
2018 & ECOSTRESS onboard ISS (spatial resolution 69 m, and revisit: daily) \\
2019 & Contextual TSEB for component temperature estimation (TSEB-2T) \\
\hline
\end{tabular}

\section{Acknowledgments}

We would like to thank the editor and the anonymous reviewers for their valuable comments and suggestions, which helped to improve this work.

\section{References}

1. H. L. Penman, "Natural evaporation from open water, bare soil and grass," Proc. R. Soc. London A 193(1032), 120-145 (1948).

2. J. Monteith, G. Szeicz, and P. Waggoner, "The measurement and control of stomatal resistance in the field," J. Appl. Ecol. 2, 345-355 (1965).

3. B. Choudhury, R. Reginato, and S. Idso, "An analysis of infrared temperature observations over wheat and calculation of latent heat flux," Agric. For. Meteorol. 37(1), 75-88 (1986).

4. J. D. Kalma, T. R. McVicar, and M. F. McCabe, "Estimating land surface evaporation: a review of methods using remotely sensed surface temperature data," Surv. Geophys. 29(4-5), 421-469 (2008).

5. H. T. Brown et al., "VIII. Static diffusion of gases and liquids in relation to the assimilation of carbon and translocation in plants," Philos. Trans. R. Soc. London B 193(185-193), 223-291 (1900).

6. J. Monteith, "Coupling of plants to the atmosphere," in Symp.-Br. Ecol. Soc. (1981).

7. R. G. Allen et al., "Crop evapotranspiration-guidelines for computing crop water requirements-FAO irrigation and drainage paper 56," FAO, Rome 300(9), D05109 (1998).

8. A. Chamberlain, "Transport of gases to and from surfaces with bluff and wave-like roughness elements," Q. J. R. Meteorol. Soc. 94(401), 318-332 (1968).

9. J. Ham and J. Heilman, "Aerodynamic and surface resistances affecting energy transport in a sparse crop," Agric. For. Meteorol. 53(4), 267-284 (1991).

10. W. J. Shuttleworth and J. llace, "Evaporation from sparse crops-an energy combination theory," Q. J. R. Meteorol. Soc. 111(469), 839-855 (1985).

11. L. Gu et al., "Micrometeorology, biophysical exchanges and nee decomposition in a twostory boreal forest-development and test of an integrated model," Agric. For. Meteorol. 94(2), 123-148 (1999).

12. W. Brutsaert and M. Sugita, "Sensible heat transfer parameterization for surfaces with anisothermal dense vegetation," J. Atmos. Sci. 53(2), 209-216 (1996).

13. W. Kustas and J. Norman, "Use of remote sensing for evapotranspiration monitoring over land surfaces," Hydrol. Sci. J. 41(4), 495-516 (1996).

14. D. Troufleau et al., "Sensible heat flux and radiometric surface temperature over sparse Sahelian vegetation. I. An experimental analysis of the $K B^{-1}$ parameter," J. Hydrol. 188 , 815-838 (1997).

15. A. Verhoef, H. De Bruin, and B. Van Den Hurk, "Some practical notes on the parameter $K B^{-1}$ for sparse vegetation," J. Appl. Meteorol. 36(5), 560-572 (1997). 
16. Z. Su et al., "An evaluation of two models for estimation of the roughness height for heat transfer between the land surface and the atmosphere," J. Appl. Meteorol. 40(11), 1933-1951 (2001).

17. W. P. Kustas et al., "Determination of sensible heat flux over sparse canopy using thermal infrared data," Agric. For. Meteorol. 44(3-4), 197-216 (1989).

18. A. Chehbouni et al., "Examination of the difference between radiative and aerodynamic surface temperatures over sparsely vegetated surfaces," Remote Sens. Environ. 58(2), 177-186 (1996).

19. W. G. Bastiaanssen et al., "A remote sensing surface energy balance algorithm for land (SEBAL). 1. Formulation," J. Hydrol. 212, 198-212 (1998).

20. Q. Zhuang et al., "A method for sensible heat flux model parameterization based on radiometric surface temperature and environmental factors without involving the parameter KB $B^{-1}$, Int. J. Appl. Earth Obs. Geoinf. 47, 50-59 (2016).

21. R. G. Allen, M. Tasumi, and R. Trezza, "Satellite-based energy balance for mapping evapotranspiration with internalized calibration (METRIC) model," J. Irrig. Drain. Eng. 133(4), 380-394 (2007).

22. R. Jackson, R. Reginato, and S. Idso, "Wheat canopy temperature: a practical tool for evaluating water requirements," Water Resour. Res. 13(3), 651-656 (1977).

23. A. Dyer, "The turbulent transport of heat and water vapour in an unstable atmosphere," Q. J. R. Meteorolog. Soc. 93(398), 501-508 (1967).

24. J. A. Businger et al., "Flux-profile relationships in the atmospheric surface layer," J. Atmos. Sci. 28(2), 181-189 (1971).

25. C. A. Paulson, "The mathematical representation of wind speed and temperature profiles in the unstable atmospheric surface layer," J. Appl. Meteorol. 9(6), 857-861 (1970).

26. M. S. Moran et al., "Mapping surface energy balance components by combining landsat thematic mapper and ground-based meteorological data," Remote Sens. Environ. 30(1), 77-87 (1989).

27. L. Mahrt and M. Ek, "The influence of atmospheric stability on potential evaporation," J. Clim. Appl. Meteor. 23(2), 222-234 (1984).

28. J. Hatfield, D. Wanjura, and G. Barker, "Canopy temperature response to water stress under partial canopy," Trans. ASAE 28(5), 1607-1611 (1985).

29. D. Courault, B. Seguin, and A. Olioso, "Review on estimation of evapotranspiration from remote sensing data: from empirical to numerical modeling approaches," Irrig. Drain. Syst. 19(3-4), 223-249 (2005).

30. N. Bhattarai et al., "Evaluating five remote sensing based single-source surface energy balance models for estimating daily evapotranspiration in a humid subtropical climate," Int. J. Appl. Earth Obs. Geoinf. 49, 75-86 (2016).

31. Elsevier, https://www.scopus.com/ (accessed 23 January 2020).

32. M. Kottek et al., "World map of the Köppen-Geiger climate classification updated," Meteorol. Z. 15(3), 259-263 (2006).

33. Z. Su, "The surface energy balance system (SEBS) for estimation of turbulent heat fluxes," Hydrol. Earth Syst. Sci. 6(1), 85-100 (2002).

34. R. Allen et al., "Satellite-based ET estimation in agriculture using SEBAL and METRIC," Hydrol. Process. 25(26), 4011-4027 (2011).

35. A. Kilic et al., "Sensitivity of evapotranspiration retrievals from the metric processing algorithm to improved radiometric resolution of Landsat 8 thermal data and to calibration bias in Landsat 7 and 8 surface temperature," Remote Sens. Environ. 185, 198-209 (2016).

36. R. K. Singh et al., "Application of sebal model for mapping evapotranspiration and estimating surface energy fluxes in south-central Nebraska," J. Irrig. Drain. Eng. 134(3), 273285 (2008).

37. C. G. Morton et al., "Assessing calibration uncertainty and automation for estimating evapotranspiration from agricultural areas using metric," JAWRA J. Am. Water Resour. Assoc. 49(3), 549-562 (2013).

38. S. Dhungel and M. Barber, "Estimating calibration variability in evapotranspiration derived from a satellite-based energy balance model," Remote Sens. 10(11), 1695 (2018). 
39. M. P. Mohan, K. Rajitha, and M. R. Varma, "Integration of soil moisture as an auxiliary parameter for the anchor pixel selection process in SEBAL using Landsat 8 and Sentinel-1a images," Int. J. Remote Sens. 41(3), 1214-1231 (2020).

40. R. G. Allen et al., "Automated calibration of the metric-landsat evapotranspiration process," JAWRA J. Am. Water Resour. Assoc. 49(3), 563-576 (2013).

41. N. Bhattarai et al., "A new optimized algorithm for automating endmember pixel selection in the SEBAL and METRIC models," Remote Sens. Environ. 196, 178-192 (2017).

42. A. M. Silva, R. M. da Silva, and C. A. G. Santos, "Automated surface energy balance algorithm for land (ASEBAL) based on automating endmember pixel selection for evapotranspiration calculation in MODIS orbital images," Int. J. Appl. Earth Obs. Geoinf. 79, 1-11 (2019).

43. M. Raupach, "Simplified expressions for vegetation roughness length and zero-plane displacement as functions of canopy height and area index," Boundary Layer Meteorol. 71(1-2), 211-216 (1994).

44. M. Gokmen et al., "Integration of soil moisture in SEBS for improving evapotranspiration estimation under water stress conditions," Remote Sens. Environ. 121, 261-274 (2012).

45. A. Ghulam et al., "Modified perpendicular drought index (MPDI): a real-time drought monitoring method," ISPRS J. Photogramm. Remote Sens. 62(2), 150-164 (2007).

46. C. Huang et al., "Improving estimation of evapotranspiration under water-limited conditions based on SEBS and MODIS data in arid regions," Remote Sens. 7(12), 16795-16814 (2015).

47. R. K. Singh and A. Irmak, "Treatment of anchor pixels in the metric model for improved estimation of sensible and latent heat fluxes," Hydrol. Sci. J. 56(5), 895-906 (2011).

48. M. Mkhwanazi, J. L. Chávez, and E. H. Rambikur, "Comparison of large aperture scintillometer and satellite-based energy balance models in sensible heat flux and crop evapotranspiration determination," Int. J. Remote Sens. Appl. 2(1), 24-30 (2012).

49. R. Madugundu et al., "Performance of the metric model in estimating evapotranspiration fluxes over an irrigated field in Saudi Arabia using Landsat-8 images," Hydrol. Earth Syst. Sci. 21(12), 6135-6151 (2017).

50. J. Van der Kwast et al., "Evaluation of the surface energy balance system (SEBS) applied to aster imagery with flux-measurements at the sparc 2004 site (Barrax, Spain)," Hydrol. Earth Syst. Sci. Discuss. 6(1), 1165-1196 (2009).

51. K. Byun, U. W. Liaqat, and M. Choi, "Dual-model approaches for evapotranspiration analyses over homo-and heterogeneous land surface conditions," Agric. For. Meteorol. 197, 169-187 (2014).

52. E. Webster, D. Ramp, and R. T. Kingsford, "Incorporating an iterative energy restraint for the surface energy balance system (SEBS)," Remote Sens. Environ. 198, 267-285 (2017).

53. R. Allen et al., "Mapping evapotranspiration at high resolution, applications manual for landsat satellite imagery," Version 2(7), 248 (2010).

54. D. Long and V. P. Singh, "A modified surface energy balance algorithm for land (M-SEBAL) based on a trapezoidal framework," Water Resour. Res. 48(2), 2528 (2012).

55. M. Choi et al., "An intercomparison of three remote sensing-based surface energy balance algorithms over a corn and soybean production region (IOWA, US) during SMACEX," Agric. For. Meteorol. 149(12), 2082-2097 (2009).

56. Y. Ma et al., "Estimations of regional surface energy fluxes over heterogeneous Oasis-desert surfaces in the middle reaches of the Heihe river during HiWATER-MUSOEXE," IEEE Geosci. Remote Sens. Lett. 12(3), 671-675 (2015).

57. G. Roerink, Z. Su, and M. Menenti, "S-SEBI: a simple remote sensing algorithm to estimate the surface energy balance," Phys. Chem. Earth Part B 25(2), 147-157 (2000).

58. M. Menenti et al., "Linear relationships between surface reflectance and temperature and their application to map actual evaporation of groundwater," Adv. Space Res. 9(1), 165-176 (1989).

59. M. García et al., "Comparison of three operative models for estimating the surface water deficit using ASTER reflective and thermal data," Sensors 7(6), 860-883 (2007).

60. C. Mattar et al., "Impacts of the broadband albedo on actual evapotranspiration estimated by S-SEBI model over an agricultural area," Remote Sens. Environ. 147, $23-42$ (2014). 
61. N. Bhattarai et al., "Utility of remote sensing-based surface energy balance models to track water stress in rain-fed switchgrass under dry and wet conditions," ISPRS J. Photogramm. Remote Sens. 133, 128-141 (2017).

62. R. D. Jackson et al., "Canopy temperature as a crop water stress indicator," Water Resour. Res. 17(4), 1133-1138 (1981).

63. M. Menenti and B. Choudhury, "Parameterization of land surface evapotranspiration using a location dependent potential evapotranspiration and surface temperature range," in Exchange Process. Land Surface Range Space and Time Scales, Vol. 212, pp. 561-568 (1993).

64. L. Jia et al., "Evaluation of the surface energy balance index with the field and airborne data collected at Hartheim and Colmar," in Digital Airborne Spectrometer Exp., Vol. 499, p. 235 (2001).

65. G. B. Senay et al., "Operational evapotranspiration mapping using remote sensing and weather datasets: a new parameterization for the SSEB approach," JAWRA J. Am. Water Resour. Assoc. 49(3), 577-591 (2013).

66. J. Lian and M. Huang, "Comparison of three remote sensing based models to estimate evapotranspiration in an oasis-desert region," Agric. Water Manage. 165, 153-162 (2016).

67. R. Tang et al., "An intercomparison of three remote sensing-based energy balance models using large aperture scintillometer measurements over a wheat-corn production region," Remote Sens. Environ. 115(12), 3187-3202 (2011).

68. W. J. Timmermans et al., "An intercomparison of the surface energy balance algorithm for land (SEBAL) and the two-source energy balance (TSEB) modeling schemes," Remote Sens. Environ. 108(4), 369-384 (2007).

69. J. M. Norman, W. P. Kustas, and K. S. Humes, "Source approach for estimating soil and vegetation energy fluxes in observations of directional radiometric surface temperature," Agric. For. Meteorol. 77(3-4), 263-293 (1995).

70. P. D. Colaizzi et al., "Two-source energy balance model estimates of evapotranspiration using component and composite surface temperatures," Adv. Water Resour. 50, 134-151 (2012).

71. N. Agam et al., "Application of the Priestley-Taylor approach in a two-source surface energy balance model," J. Hydrometeorol. 11(1), 185-198 (2010).

72. J. B. Fisher, K. P. Tu, and D. D. Baldocchi, "Global estimates of the land-atmosphere water flux based on monthly AVHRR and ISLSCP-II data, validated at 16 fluxnet sites," Remote Sens. Environ. 112(3), 901-919 (2008).

73. G. Gan and Y. Gao, "Estimating time series of land surface energy fluxes using optimized two source energy balance schemes: model formulation, calibration, and validation," Agric. For. Meteorol. 208, 62-75 (2015).

74. P. D. Colaizzi et al., "Two-source energy balance model to calculate E, T, and ET: comparison of Priestley-Taylor and Penman-Monteith formulations and two time scaling methods," Trans. ASABE 57(2), 479-498 (2014).

75. Y. Yang et al., "Intercomparison of three two-source energy balance models for partitioning evaporation and transpiration in semiarid climates," Remote Sens. 10(7), 1149 (2018).

76. M. Anderson et al., "A two-source time-integrated model for estimating surface fluxes using thermal infrared remote sensing," Remote Sens. Environ. 60(2), 195-216 (1997).

77. J. R. Mecikalski et al., "Estimating fluxes on continental scales using remotely sensed data in an atmospheric-land exchange model," J. Appl. Meteorol. 38(9), 1352-1369 (1999).

78. K. McNaughton and T. Spriggs, "A mixed-layer model for regional evaporation," Boundary Layer Meteorol. 34(3), 243-262 (1986).

79. M. C. Anderson, W. P. Kustas, and J. M. Norman, "Upscaling and downscaling a regional view of the soil-plant-atmosphere continuum," Agron. J. 95(6), 1408-1423 (2003).

80. M. Moran et al., "Estimating crop water deficit using the relation between surface-air temperature and spectral vegetation index," Remote Sens. Environ. 49(3), 246-263 (1994).

81. T. Carlson, "An overview of the "triangle method' for estimating surface evapotranspiration and soil moisture from satellite imagery," Sensors 7(8), 1612-1629 (2007). 
82. T. N. Carlson, R. R. Gillies, and E. M. Perry, "A method to make use of thermal infrared temperature and NDVI measurements to infer surface soil water content and fractional vegetation cover," Remote Sens. Rev. 9(1-2), 161-173 (1994).

83. D. Long and V. P. Singh, "A two-source trapezoid model for evapotranspiration (TTME) from satellite imagery," Remote Sens. Environ. 121, 370-388 (2012).

84. J. Tian et al., "Impact of the spatial domain size on the performance of the TS-VI triangle method in terrestrial evapotranspiration estimation," Remote Sens. 5(4), 1998-2013 (2013).

85. H. Sun, "A two-source model for estimating evaporative fraction (TMEF) coupling Priestley-Taylor formula and two-stage trapezoid," Remote Sens. 8(3), 248 (2016).

86. Y. Yang and S. Shang, "A hybrid dual-source scheme and trapezoid framework-based evapotranspiration model (HTEM) using satellite images: algorithm and model test," J. Geophys. Res. Atmos. 118(5), 2284-2300 (2013).

87. Y. Yang et al., "An enhanced two-source evapotranspiration model for land (ETEML): algorithm and evaluation," Remote Sens. Environ. 168, 54-65 (2015).

88. D. S. Kimes et al., "View angle effects in the radiometric measurement of plant canopy temperatures," Remote Sens. Environ. 10(4), 273-284 (1980).

89. L. Song et al., "Estimation of surface heat fluxes using multi-angular observations of radiative surface temperature," Remote Sens. Environ. 239, 111674 (2020).

90. W. P. Kustas and J. M. Norman, "A two-source approach for estimating turbulent fluxes using multiple angle thermal infrared observations," Water Resour. Res. 33(6), 1495-1508 (1997).

91. L. Jia et al., "A practical algorithm to infer soil and foliage component temperatures from bi-angular ATSR-2 data," Int. J. Remote Sens. 24(23), 4739-4760 (2003).

92. J. Sánchez et al., "Modelling surface energy fluxes over maize using a two-source patch model and radiometric soil and canopy temperature observations," Remote Sens. Environ. 112(3), 1130-1143 (2008).

93. S. Manfreda et al., "On the use of unmanned aerial systems for environmental monitoring," Remote Sens. 10(4), 641 (2018).

94. H. Niu et al., "Evapotranspiration estimation with UAVs in agriculture: a review," https:// www.preprints.org/manuscript/201907.0124/v1 (2019).

95. H. Nieto et al., "Evaluation of TSEB turbulent fluxes using different methods for the retrieval of soil and canopy component temperatures from UAV thermal and multispectral imagery," Irrig. Sci. 37(3), 389-406 (2019).

96. W. J. Timmermans, W. P. Kustas, and A. Andreu, "Utility of an automated thermalbased approach for monitoring evapotranspiration,” Acta Geophys. 63(6), 1571-1608 (2015).

97. C. Brenner et al., "Estimation of evapotranspiration of temperate grassland based on highresolution thermal and visible range imagery from unmanned aerial systems," Int. J. Remote Sens. 39(15-16), 5141-5174 (2018).

98. J. Deardorff, G. Willis, and B. Stockton, "Laboratory studies of the entrainment zone of a convectively mixed layer," J. Fluid Mech. 100(1), 41-64 (1980).

99. T. Bonin et al., "Observations of the early evening boundary-layer transition using a small unmanned aerial system," Boundary Layer Meteorol. 146(1), 119-132 (2013).

100. M.-S. Kim and B. H. Kwon, "Estimation of sensible heat flux and atmospheric boundary layer height using an unmanned aerial vehicle," Atmosphere 10(7), 363 (2019).

101. D. E. Strebel et al., "The fife information system," IEEE Trans. Geosci. Remote Sens. 28(4), 703-710 (1990).

102. L. Z. Zhirong and M. McDonnell, "Atmospheric correction of thermal infrared images," Int. J. Remote Sens. 9(1), 107-121 (1988).

103. T. Xu et al., "Mapping regional turbulent heat fluxes via variational assimilation of land surface temperature data from polar orbiting satellites," Remote Sens. Environ. 221, 444-461 (2019).

104. T. Xu, S. M. Bateni, and S. Liang, "Estimating turbulent heat fluxes with a weak-constraint data assimilation scheme: a case study (HiWATER-MUSOEXE)," IEEE Geosci. Remote Sens. Lett. 12(1), 68-72 (2015). 
105. F. Caparrini, F. Castelli, and D. Entekhabi, "Estimation of surface turbulent fluxes through assimilation of radiometric surface temperature sequences," J. Hydrometeorol. 5(1), 145-159 (2004).

106. F. Sini et al., "Estimation of large-scale evaporation fields based on assimilation of remotely sensed land temperature," Water Resour. Res. 44(6), W06410 (2008).

107. A. Abdolghafoorian and L. Farhadi, "Estimation of surface turbulent fluxes from land surface moisture and temperature via a variational data assimilation framework," Water Resour. Res. 55(6), 4648-4667 (2019).

108. S. Bateni and D. Entekhabi, "Surface heat flux estimation with the ensemble Kalman smoother: joint estimation of state and parameters," Water Resour. Res. 48(8), 8521 (2012).

109. R. Eswar, M. Sekhar, and B. Bhattacharya, "Comparison of three remote sensing based models for the estimation of latent heat flux over India," Hydrol. Sci. J. 62(16), 2705-2719 (2017).

110. J. M. Hendrickx et al., "Scintillometer networks for calibration and validation of energy balance and soil moisture remote sensing algorithms," Proc. SPIE 6565, 65650W (2007).

111. M. Tasumi et al., "Operational aspects of satellite-based energy balance models for irrigated crops in the semi-arid us," Irrig. Drain. Syst. 19(3-4), 355-376 (2005).

112. B. G. Bezerra et al., "Actual evapotranspiration estimation using remote sensing: comparison of SEBAL and SSEB approaches," Adv. Remote Sens. 4(3), 234 (2015).

113. L. Jia et al., "Estimation of sensible heat flux using the surface energy balance system (SEBS) and ATSR measurements," Phys. Chem. Earth Parts A/B/C 28(1-3), 75-88 (2003).

114. Z. Su et al., "Assessing relative soil moisture with remote sensing data: theory, experimental validation, and application to drought monitoring over the North China Plain,' Phys. Chem. Earth Parts A/B/C 28(1-3), 89-101 (2003).

115. G. B. Senay et al., "A coupled remote sensing and simplified surface energy balance approach to estimate actual evapotranspiration from irrigated fields," Sensors 7(6), 979-1000 (2007).

116. P. Gowda et al., "Lysimetric evaluation of simplified surface energy balance approach in the Texas high plains," Appl. Eng. Agric. 25(5), 665-669 (2009).

117. M. R. Lurtz et al., "Relationships between Riparian evapotranspiration and groundwater depth along a semiarid irrigated river valley," Hydrol. Process. 34(8), 1714-1727 (2020).

118. A. M. Melesse and V. Nangia, "Estimation of spatially distributed surface energy fluxes using remotely-sensed data for agricultural fields," Hydrol. Process. 19(14), 2653-2670 (2005).

119. J. Norman et al., "Remote sensing of surface energy fluxes at 101-m pixel resolutions," Water Resour. Res. 39(8) (2003).

120. M. C. Anderson et al., "Mapping daily evapotranspiration at landsat spatial scales during the Bearex'08 field campaign," Adv. Water Resour. 50, 162-177 (2012).

121. J. Sánchez et al., "Monitoring daily evapotranspiration at a regional scale from LandsatTM and ETM+ data: application to the Basilicata region," J. Hydrol. 351(1-2), 58-70 (2008).

122. A. Andreu et al., "Influence of component temperature derivation from dual angle thermal infrared observations on TSEB flux estimates over an irrigated vineyard," Acta Geophys. 63(6), 1540-1570 (2015).

123. Y. Yang, R. L. Scott, and S. Shang, "Modeling evapotranspiration and its partitioning over a semiarid shrub ecosystem from satellite imagery: a multiple validation," J. Appl. Remote Sens. 7(1), 073495 (2013).

124. Z. Sun et al., "Development of a simple remote sensing evapotranspiration model (SIM-RESET): algorithm and model test," J. Hydrol. 376(3-4), 476-485 (2009).

125. Z. Sun et al., "Further evaluation of the SIM-RESET model for et estimation driven by only satellite inputs," Hydrol. Sci. J. 58(5), 994-1012 (2013).

126. R. Tang and Z.-L. Li, "An end-member-based two-source approach for estimating land surface evapotranspiration from remote sensing data," IEEE Trans. Geosci. Remote Sens. 55(10), 5818-5832 (2017). 
127. Y. Jiang et al., "Estimation of soil evaporation and vegetation transpiration using two trapezoidal models from MODIS data," J. Geophys. Res. Atmos. 124(14), 7647-7664 (2019).

128. Y. Yang et al., "A one-source approach for estimating land surface heat fluxes using remotely sensed land surface temperature," Remote Sens. 9(1), 43 (2017).

129. Y. Yang et al., "Evaluation of a two-source energy balance model for estimating regional land surface heat fluxes during the HiWATER-MUSOEXE," in 7th Int. Conf. Agro-geoinf., IEEE, pp. 1-5 (2018).

130. P. Wagle et al., "Performance of five surface energy balance models for estimating daily evapotranspiration in high biomass Sorghum," ISPRS J. Photogramm. Remote Sens. 128, 192-203 (2017).

131. Z. Su, H. Pelgrum, and M. Menenti, "Aggregation effects of surface heterogeneity in land surface processes," Hydrol. Earth Syst. Sci. 3(4), 549-563 (1999).

132. W. Kustas et al., "Effects of remote sensing pixel resolution on modeled energy flux variability of croplands in IOWA," Remote Sens. Environ. 92(4), 535-547 (2004).

133. J. M. Ramírez-Cuesta et al., "Impact of the spatial resolution on the energy balance components on an open-canopy Olive Orchard," Int. J. Appl. Earth Obs. Geoinf. 74, 88-102 (2019).

134. V. Sharma, A. Kilic, and S. Irmak, "Impact of scale/resolution on evapotranspiration from Landsat and MODIS images," Water Resour. Res. 52(3), 1800-1819 (2016).

135. M. Gebremichael, J. Wang, and T. W. Sammis, "Dependence of remote sensing evapotranspiration algorithm on spatial resolution," Atmos. Res. 96(4), 489-495 (2010).

136. P. Teluguntla et al., "Impact of spatial scale on remotely sensed evapotranspiration estimates from heterogeneous land surfaces," in 19th Int. Cong. Modell. and Simul., Perth (2011).

137. C. Cammalleri et al., "Applications of a remote sensing-based two-source energy balance algorithm for mapping surface fluxes without in situ air temperature observations," Remote Sens. Environ. 124, 502-515 (2012).

138. B. Yu et al., "Mapping daily evapotranspiration over a large irrigation district from MODIS data using a novel hybrid dual-source coupling model," Agric. For. Meteorol. 276, 107612 (2019).

139. Y. Yao et al., "A simple temperature domain two-source model for estimating agricultural field surface energy fluxes from landsat images," J. Geophys. Res. Atmos. 122(10), 5211-5236 (2017).

140. V. Döpper et al., "Challenges in UAS-based TIR imagery processing: image alignment and uncertainty quantification," Remote Sens. 12(10), 1552 (2020).

141. A. Amazirh, O. Merlin, and S. Er-Raki, "Including Sentinel-1 radar data to improve the disaggregation of MODIS land surface temperature data," ISPRS J. Photogramm. Remote Sens. 150, 11-26 (2019).

142. A. Karnieli et al., "Comments on the use of the vegetation health index over Mongolia," Int. J. Remote Sens. 27(10), 2017-2024 (2006).

143. R. Qiu et al., "Evapotranspiration estimation using a modified Priestley-Taylor model in a rice-wheat rotation system," Agric. Water Manage. 224, 105755 (2019).

144. D. Entekhabi et al., "The soil moisture active passive (SMAP) mission," Proc. IEEE 98(5), 704-716 (2010).

145. E. Santi et al., "On the synergy of SMAP, AMSR2 and Sentinel-1 for retrieving soil moisture," Int. J. Appl. Earth Obs. Geoinf. 65, 114-123 (2018).

146. M. Giblett, "Some problems connected with evaporation from large expanses of water," Proc. R. Soc. London Ser. A 99(701), 472-490 (1921).

147. E. M. Crowther, "The relationship of climatic and gelogical factors to the composition of soil clay and the distribution of soil types," Proc. R. Soc. London Ser. B 107(748), 1-30 (1930).

148. H. Penman and B. Keen, "Meteorological and soil factors affecting evaporation from fallow soil," Q. J. R. Meteorolog. Soc. 66(287), 401-410 (1940).

149. H. T. Penman, "Some physical aspects of assimilation and transpiration," in Symp. Soc. Exptl. Biol., Vol. 5, pp. 115-129 (1951). 
150. A. Monin and A. Obukhov, "Basic laws of turbulent mixing in the ground layer of the atmosphere (osnovne zakonomernosti turbulentnogo peremeshivaniya v prizemnom sloe atmosfery)," Tech. Rep., American Meteorological Society, Boston, MA (1959).

151. J. Businger, "Some remarks on Penman's equations for the evapotranspiration," Netherlands J. Agric. Sci 4, 77 (1956).

152. C. Tanner and W. Pelton, "Potential evapotranspiration estimates by the approximate energy balance method of Penman," J. Geophys. Res. 65(10), 3391-3413 (1960).

153. H. Penman and I. Long, "Weather in wheat: an essay in micro-meteorology," $Q$. J. R. Meteorolog. Soc. 86(367), 16-50 (1960).

154. J. L. Monteith and G. Szeicz, "Radiative temperature in the heat balance of natural surfaces," Q. J. R. Meteorolog. Soc. 88(378), 496-507 (1962).

155. D. M. Gates, "Leaf temperature and energy exchange," Arch. Meteorol. Geophys. Bioklimatol. Ser. B 12(2), 321-336 (1962).

156. D. Q. Wark, G. Yamamoto, and J. H. Lienesch, "Methods of estimating infrared flux and surface temperature from meteorological satellites," J. Atmos. Sci. 19(5), 369-384 (1962).

157. A. Dyer and B. Hicks, "Flux-gradient relationships in the constant flux layer," $Q$. J. R. Meteorolog. Soc. 96(410), 715-721 (1970).

158. J. Bartholic, L. Namkem, and C. Wiegand, "Aerial thermal scanner to determine temperatures of soils and of crop canopies differing in water stress 1," Agron. J. 64(5), 603-608 (1972).

159. C. Priestley and R. Taylor, "On the assessment of surface heat flux and evaporation using large-scale parameters," Mon. Weather Rev. 100(2), 81-92 (1972).

160. J. Heilman et al., "Thermal scanner measurement of canopy temperatures to estimate evapotranspiration," Remote Sens. Environ. 5, 137-145 (1976).

161. A. Rosema et al., "Tellus: a combined surface temperature, soil moisture and evaporation mapping approach," in Proc. Symp. Remote Sens., Environmental Research Institute of Michigan, Vol. 3, pp. 2267-2276 (1978).

162. O. Taconet, R. Bernard, and D. Vidal-Madjar, "Evapotranspiration over an agricultural region using a surface flux/temperature model based on NOAA-AVHRR data," J. Clim. Appl. Meteorol. 25(3), 284-307 (1986).

163. J. Wieringa, "Roughness-dependent geographical interpolation of surface wind speed averages," Q. J. R. Meteorolog. Soc. 112(473), 867-889 (1986).

164. J. Gash, "An analytical framework for extrapolating evaporation measurements by remote sensing surface temperature," Int. J. Remote Sens. 8(8), 1245-1249 (1987).

165. W. Shuttleworth et al., "Fife: the variation in energy partition at surface flux sites," in Proc. LAHS Third Int. Assembly, IAHS Publication, Vol. 186, No. 6, pp. 67-74 (1989).

166. W. Massman, "A model study of kbh-1 for vegetated surfaces using localized near-field Lagrangian theory," J. Hydrol. 223(1-2), 27-43 (1999).

167. R. Zhang et al., "An operational two-layer remote sensing model to estimate surface flux in regional scale: physical background," Sci. China Ser. D 48(Suppl. 1), 225 (2005).

168. S. P. Loheide, II and S. M. Gorelick, "A local-scale, high-resolution evapotranspiration mapping algorithm (ETMA) with hydroecological applications at Riparian Meadow restoration sites," Remote Sens. Environ. 98(2-3), 182-200 (2005).

169. G. Boulet et al., "The sparse model for the prediction of water stress and evapotranspiration components from thermal infra-red data and its evaluation over irrigated and rainfed wheat," Hydrol. Earth Syst. Sci. 19(11), 4653-4672 (2015).

170. R. Dhungel et al., "Evapotranspiration between satellite overpasses: methodology and case study in agricultural dominant semi-arid areas," Meteorol. Appl. 23(4), 714-730 (2016).

M. M. Prakash Mohan is currently pursuing his $\mathrm{PhD}$ in the field of advanced remote sensing applications for surface energy balance models at BITS Pilani-Hyderabad Campus. He has 10 years of field experience as a designer for microirrigation systems for diverse environmental and terrain conditions. His expertise contributed relevant research publications in the domain of modification of approaches applied for remote sensing-based ET modeling using the SAR dataset. 
Rajitha Kanchirapuzha received her $\mathrm{PhD}$ in remote sensing applications for water resources management at IIT Kharagpur in 2007. She is currently working as an assistant professor at BITS Pilani-Hyderabad campus. Her expertise mainly includes remote sensing applications for agriculture, aquaculture, natural resources, and wetland management. She is currently involved in the process of applying advanced remote sensing datasets for developing algorithms for various agriculture and allied areas.

Murari R. R. Varma received his $\mathrm{PhD}$ in watershed hydrology and management from the Indian Institute of Science, Bangalore, in 2010. He is currently working as an assistant professor at BITS Pilani-Hyderabad campus. He has expertise in the domains of experimental and field hydrology, hydrochemistry of watersheds, GIS applications in hydrology, and environmental hydrology. 